\title{
Classificação morfodinâmica das praias arenosas de Ipojuca (Pernambuco, Brasil) através da análise semântica de imagens de satélite pancromáticas
}

\author{
Daniele MALLMANN, Pedro PEREIRA, Fabio SANTOS \& Patrícia FAÇANHA
}

Departamento de Oceanografia, Universidade Federal de Pernambuco. Avenida da Arquitetura, s/n, Cidade Universitária, CEP: 50740-550, Recife, PE, Brasil.Email: danielemallmann@gmail.com, psppraias@gmail.com, fabiompf@yahoo.com.br, patriciafacanha@gmail.com

Recebido em 01/2014. Aceito para publicação em 08/2014.

Versão online publicada em 19/09/2014 (www.pesquisasemgeociencias.ufrgs.br)

\begin{abstract}
Resumo - Este artigo apresenta a classificação morfodinâmica das praias do município de Ipojuca, sul de Pernambuco, através da análise semântica de imagens de satélite disponibilizadas pelo Google Earth. Foram analisadas 61 imagens, nas quais foram observadas feições indicadoras de estágios morfodinâmicos segundo modelos propostos para praias dominadas por ondas, pela maré, modificadas pela maré e controladas pela geomorfologia. A partir das imagens estudadas foi possível constatar a presença/ausência de feições tridimensionais, além de identificar agentes geomorfológicos controladores da hidrodinâmica costeira. Tais observações abrangeram a zona de surfe, a praia e a pós-praia. Apesar da pequena extensão $(<30 \mathrm{~km})$, o litoral em questão apresenta uma grande diversidade de ambientes praiais, o que reflete na ocorrência de distintos estágios morfodinâmicos e na dominância das várias forçantes como agentes modeladores das praias arenosas analisadas.
\end{abstract}

Palavras-chave: zona de surfe, feições tridimensionais, imagens de satélite.

\begin{abstract}
Morphodynamic Classification of IpojuCA's SANDY BEACHES (PERnAmbuco, BRAZIL) TROUGH SEMANTIC ANALYSIS OF PANCHROMATIC SATELLITE IMAGES. This paper presents the morphodynamic classification of Ipojuca's beaches, southern of Pernambuco State through the interpretation of panchromatic satellite images freely available on Google Earth. A total of 61 images were analyzed in which morphological features were used to state the morphodynamical stages proposed for beaches dominated by waves, by tide, tide modified and controlled by coastal geomorphology. The observations included the surf zone, the swash zone and the dry beach. From the images, it was possible to identify the presence of tridimensional features at those environments, as well as the absence of it and the presence of geomorphological features that control the nearshore processes. It was possible to observe that, despite the small extension $(<30 \mathrm{~km})$, the studied coastline presents a high diversity of morphodynamic stages and the domain of distinct forces as modeling agents for these beaches.
\end{abstract}

Keywords: surf zone, tridimensional features, satellite images.

\section{Introdução}

A zona de surfe, região na qual ocorre a maior parte da dissipação da energia das ondas, constitui uma área interessante sob o ponto de vista morfodinâmico. Ali ocorre a maior parte dos processos que controlam a morfologia e a hidrodinâmica praial (Masselink \& Turner, 1999). Segundo Calliari et al. (2003), os processos responsáveis pelo comportamento das praias começam a atuar na base da antepraia, que representa o limite externo da camada limite costeira. As flutuações energéticas ali impostas por ondas, marés e correntes se manifestam em termos de variações temporais e espaciais na forma, largura, declividade, frequência de feições morfológicas secundárias, características erosivas e hidrodinâmica (Calliari \& Klein, 1993).

0 estudo da morfodinâmica praial permite integrar observações acerca da morfologia e dinâmica costeira, resultando numa descrição completa e coerente sobre o sistema praial (Calliari et al., 2003). No intui- to de compreender as alterações ocorridas na zona de surfe, Wright \& Short (1984) propuseram um modelo de classificação morfodinâmica para praias arenosas dominadas por ondas, segundo o qual, dependendo das condições ambientais, dos sedimentos e das ondas, as praias e zonas de surfe associadas podem ser enquadradas nos estágios dissipativo, refletivo ou em um dos quatro estágios intermediários. Tal referência vem, desde então, sendo amplamente utilizada para classificar praias arenosas, especialmente em regiões de micromaré (Calliari et al., 2003).

Segundo o modelo supracitado, o estágio dissipativo é representado por uma zona de surfe bem desenvolvida, com baixo gradiente topográfico e elevado estoque subaquoso de areia, sob a forma de bancos (Short, 1999). A arrebentação é predominantemente deslizante e correntes de retorno são raras (Silveira et al., 2011). Tal estado é favorecido pela incidência de ondas altas e esbeltas, bem como pela ocorrência de areia fina. No outro extremo, o estado refletivo é caracterizado pelo acen- 
tuado gradiente topográfico e pela redução da largura da zona de surfe. As ondas quebram na face da praia com grande turbulência. Nestes casos, a granulometria do sedimento tende a ser grossa e o estoque de areia se situa na porção subaérea da praia (Calliari et al., 2003).

Nos estágios intermediários ocorre gradação quanto às tendências dissipativas e refletivas da praia, a qual se traduz em diferenças morfológicas. A declividade, assim como a granulometria é moderada e feições rítmicas (bancos e cúspides) são comuns (Silveira et al., 2011). De maneira simplificada, desde o estágio dissipativo (D), uma praia pode evoluir pela progressiva redução da largura da calha longitudinal em decorrência da migração do banco submarino da zona de arrebentação em direção à praia, caracterizando o estado banco e cava longitudinais (BCL) ou longshore bar trough (LBT). 0 estágio banco e praia rítmicos (BPR) ou rhythmic bar and beach (RBB) se desenvolve quando as ondas dissipam energia no banco, se reformam na cava e atingem a face da praia em condições refletivas, criando feições rítmicas em forma de cúspides. Podem ocorrer correntes de retorno (rip currents) nas depressões entre os bancos e as condições morfodinâmicas tendem a dissipativas sobre os bancos e refletivas entre estes.

0 estado caracterizado pela presença de megacúspides, bancos dispostos transversalmente à praia e fortes correntes de retorno - banco transversal e corrente de retorno (BTR) ou transverse-bar and rip (TBR) - se desenvolve quando as extremidades dos bancos, em forma de cúspide, se soldam à face da praia. Neste estágio, as áreas rasas dos bancos, onde ocorre grande dissipação, o baixo espraiamento da onda na face da praia e o elevado empilhamento de água acima do nível médio do mar devido à ação de ondas (set up) se alternam com áreas mais inclinadas (baías), que apresentam elevado espraiamento da onda e baixo set up, apresentando máxima segregação lateral de fluxo e fortes correntes de retorno. Finalmente, o estado denominado terraço de baixamar (TBM) ou low tide terrace (LTT) apresenta o menor nível de energia entre os intermediários e se caracteriza por uma face praial íngreme, conectada no nível de baixamar a um terraço plano que pode apresentar bancos e calhas paralelos à praia e pequenas correntes de retorno minirips (Calliari et al., 2003) (Fig. 1).

De acordo com Short (2006), o litoral provê um laboratório ideal para que sejam analisados tipos de praias que podem ocorrer em resposta a um largo espectro de ondas, marés e condições sedimentares. Por este motivo, a classificação morfodinâmica supracitada não contempla a totalidade das praias possíveis em termos de tipologia e estágios morfodinâmicos. Assim, no intuito de possibilitar a classificação de praias que não se enquadram na tipologia "dominadas por ondas", Masselink \& Short (1993) propuseram um modelo para praias modificadas pela maré. Posteriormente, Short (2006) propôs modelos para praias dominadas pela maré e associadas a plataformas rochosas/recifais (Fig. 2). Desta forma, no universo das praias arenosas modificadas pela maré, figuram os estágios refletiva e terraço de baixamar ( $\mathrm{R}+\mathrm{TBM})$ ou reflective plus low tide terrace $(\mathrm{R}+\mathrm{LTT})$; refletiva e canais de baixamar $(\mathrm{R}+\mathrm{CBM})$ ou reflective plus low tide rips beaches $(\mathrm{R}+\mathrm{LT}$ rips) e ultradissipativas (UD). As primeiras se caracterizam pelo gradiente praial íngreme e cuspatado, seguido de um terraço plano. Durante a maré alta, a praia se comporta como refletiva, com ondas passando sobre o terraço e quebrando junto à face praial. Já durante a maré baixa, prevalecem características de terraço de baixamar. 0 segundo estágio difere do primeiro por apresentar maior altura de onda, na qual a energia é suficiente para abrir canais de retorno junto ao terraço, pelos quais a água flui durante a baixamar. Finalmente, as praias ultradissipativas são compostas por areia fina e se caracterizam por uma ampla zona intermareal. 0 gradiente é baixo a moderado durante a maré alta e baixo, tendendo a um perfil horizontal, durante a baixamar. A zona de arrebentação é ampla e a onda tende a dissipar continuamente sua energia. Devido ao contínuo deslocamento da zona de surfe em função do ciclo de maré, a formação de bancos é inibida.

Na categoria "praias dominadas pela maré", são descritos quatro estágios morfodinâmicos (Short, 2006). No primeiro, "praia refletiva e planícies arenosas com sulcos" (R+ planícies arenosas) ou reflective plus ridged sand flats ( $\mathrm{R}+$ sand ridges), ocorre uma praia íngreme associada a uma planície arenosa intermaré de baixo gradiente, onde ocorrem sulcos paralelos e regularmente espaçados. 0 estágio "praia e planície arenosa" (P + planície arenosa) ou beach plus sand flats $(\mathrm{B}+$ sand flats $)$ se assemelha ao anterior sem, entretanto, apresentar marcas de ondulação (ripples), visto que praias assim tendem a ocorrer em áreas onde o domínio das marés é ainda mais acentuado em detrimento da energia de ondas, insuficiente para formar feições. "Praia e planície de maré arenosa" (P+planície de maré arenosa) ou beach plus tidal sand flats (B+tidal flats) é o estágio que apresenta uma estreita e íngreme face praial composta por sedimentos grosseiros durante a maré alta, bordejada por uma extensa planície de maré arenosa (de 50 a $2500 \mathrm{~m}$ ) exposta durante a baixamar, podendo ou não apresentar manguezais frontais associados. Finalmente, naquelas praias em que a energia de maré é muito superior à das ondas, pode ocorrer o estágio denominado "Praia e planície de maré lamosa" (P+planície de maré lamosa) ou beach plus tidal mud flats (B+tidal flats/mud). Neste estágio são enquadradas praias que se localizam próximo a estuários, os quais fornecem suprimento de sedimentos finos para o desenvolvimento de planícies lamosas. Tendem a apresentar uma praia de perfil íngreme e estreito durante a preamar, associada a um terraço extenso e plano exposto durante a baixamar (de 50 a 2000 m). Eventualmente, praias com estas características podem apresentar manguezais frontais na porção intermareal superior.

Por fim, são apresentados estágios possíveis para praias bordejadas por plataformas rochosas ou 
recifais. Os mesmos incluem "praias bordejadas por plataformas rochosas intermareais" $(\mathrm{P}+$ plataformas rochosas) ou beaches fronted by intertidal rock flats (B+rock flats) e "praias bordejadas por recifes de franja" (P+recifes de franja) ou beaches fronted by fringing coral reef $(\mathrm{B}+\mathrm{coral}$ reef). Nas primeiras, os processos geológicos locais dominam em detrimento das ondas e marés, tratando-se de praias de alta energia muitas vezes associadas a costões rochosos. Já no segundo caso, as praias apresentam um perfil íngreme, sendo compostas por fragmentos grosseiros de coral. Durante a preamar, as ondas ultrapassam os recifes e atingem a praia, que apresenta características refletivas. Na baixamar, o recife é exposto e as ondas quebram na sua borda. Tais características foram descritas para praias australianas e, no caso das praias abordadas pelo presente artigo, quando da presença de recifes em franja, tem-se face praial e pós-praia suaves (Short, 2006).

Dependendo da variabilidade do clima de ondas, marés, ventos e características sedimentares, uma praia pode variar amplamente de configuração em relação ao estado mais frequente (modal), o qual é caracterizado pelas condições mais frequentes em resposta aos tipos de arrebentação e sedimento predominantes (Calliari et al., 2003). Esta transição pode se dar de maneira abrupta, sem necessariamente passar por todos os estágios intermediários.
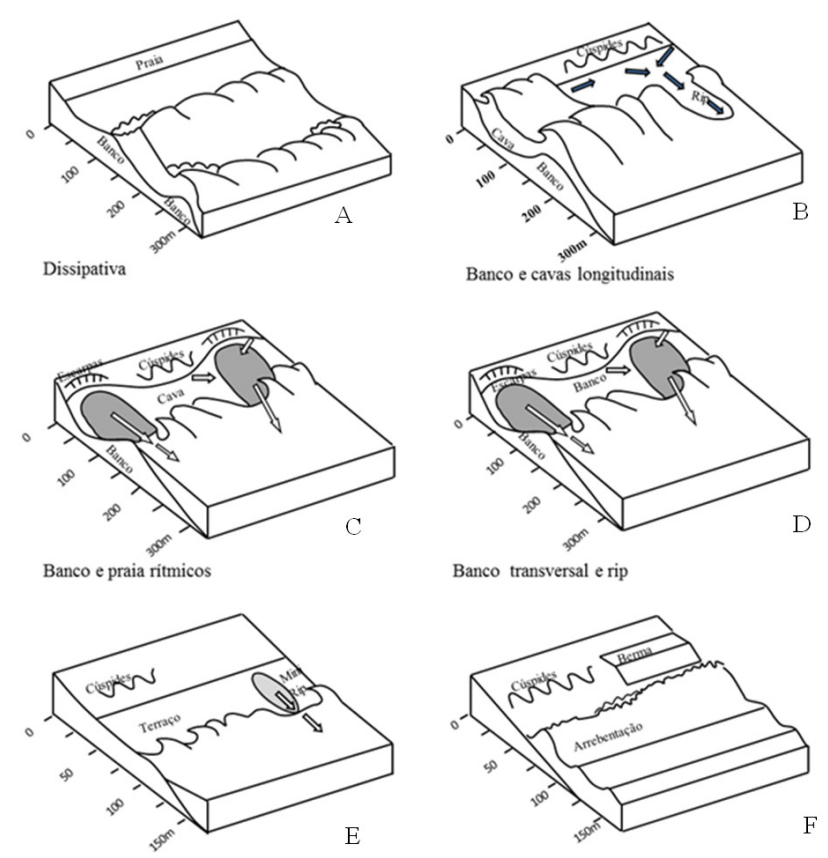

Terraço baixamar

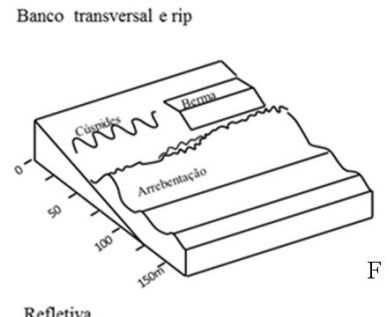

Refletiva

Figura 1. Modelo de Wright \& Short (1984) para classificação morfodinâmica de praias dominadas por ondas, incluindo os estágios: A) dissipativa; B) banco e cavas longitudinais; C) banco e praia rítmicos; D) banco transversal e rip ou corrente de retorno; E) terraço de baixamar; e F) refletiva (adaptado de SLSA, 2009).

O conhecimento acerca do estado morfodinâmico de uma praia, bem como de suas variações é de grande importância, tendo se mostrado eficiente no manejo e solução de problemas ambientais relaciona- dos às praias arenosas. 0 estabelecimento de estados modais permite determinar perigos e modos de erosão a que estão suscetíveis as diferentes praias (Calliari et al., 2003). Tal conhecimento fornece subsídios para o acompanhamento espaço-temporal de ciclos de erosão/deposição e a definição de patamares esperados de variação morfológica, aumentando o grau de sucesso de diversas ações relacionadas ao manejo de praias. Ademais, a classificação das praias quanto ao estágio morfodinâmico permite estimar o grau de periculosidade de cada estágio, podendo ser utilizada em programas de prevenção de acidentes envolvendo banhistas (Short \& Hogan, 1994).
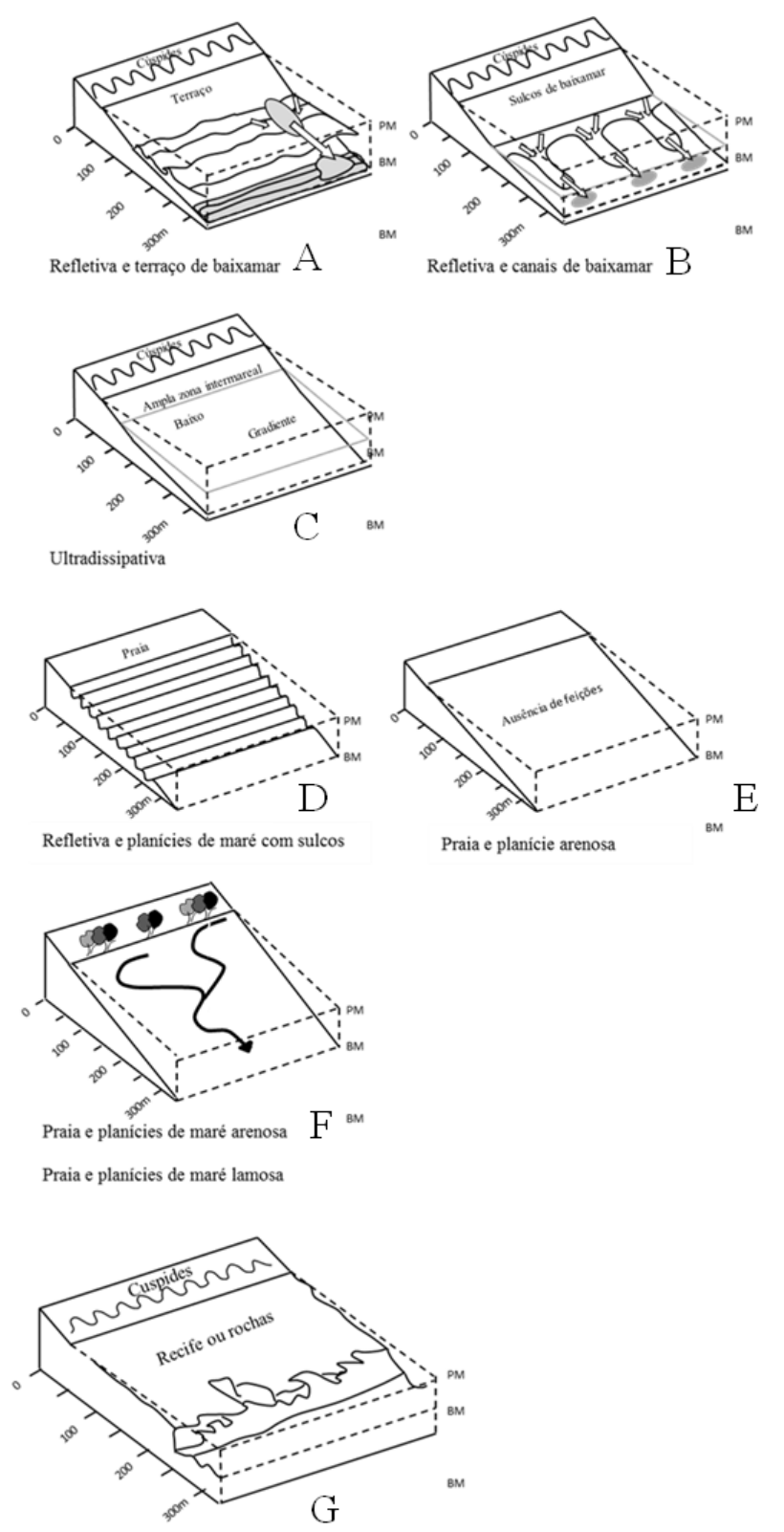

Praia bordejada por plataforma rochosa intermaré ou Praia bordejada por recifes de corais em franjas

Figura 2. Modelos de Masselink \& Short (1993) para classificação morfodinâmica de praias modificadas por marés: A) refletiva e terraço de baixamar; B) refletiva e canais de baixamar; e C) ultradissipativa; e de Short (2006) para classificação morfodinâmica de praias dominadas por marés e bordejadas por recifes em franja ou plataformas rochosas: D) refletiva e planície de maré com sulcos; E) praia e planície arenosa; F) praia e planície de maré arenosa ou lamosa; e G) praia bordejada por plataforma rochosa intermaré ou recifes de corais em franjas (adaptados de SLSA, 2009). 
Com base no supracitado, este trabalho objetiva apresentar a classificação de praias arenosas quanto ao seu estágio morfodinâmico a partir da análise semântica - ou seja, da interpretação acerca das feições observadas e do seu significado - de imagens de satélite multitemporais, além da determinação do principal agente responsável por estes estágios e suas variações - ondas, marés ou geomorfologia da costa. 0 método foi aplicado a dez praias do município de Ipojuca (Pernambuco).

\section{2 Área, materiais e métodos}

\subsection{Localização da área}

O município de Ipojuca está localizado no litoral sul de Pernambuco, entre os municípios de Cabo de Santo Agostinho (norte) e Sirinhaém (sul). Seu litoral compreende dez praias (Muro Alto, Coco Louco, Pontal do Cupe, Cupe, Porto de Galinhas, Maracaípe, Enseadinha, Serrambi, Cacimbas e Toquinho) (Fig. 3) e apresenta uma diversidade de feições morfológicas e ambientes que contempla a ocorrência de terraços marinhos, recifes (areníticos, coralíneos e calcários), depósitos de praias, manguezais e estuários (Dominguez et al., 1990).

O clima na região é considerado úmido e com uma estação seca bem definida e relativamente curta. A precipitação média anual é de cerca de $2.050 \mathrm{~mm}$ e as temperaturas médias anuais registram uma variação entre $25^{\circ} \mathrm{C}$ (mínima) e $30^{\circ} \mathrm{C}$ (máxima). Ventos predominantes são de SE, sendo que no inverno esta é a direção de maior incidência com velocidades médias entre 5,0 a $6,1 \mathrm{~m} / \mathrm{s}$. No verão, predominam os ventos alísios do quadrante $\mathrm{E}$, cujas velocidades variam em torno de 5,2 m/s (Manso, 2003).

A região está sob um regime de mesomaré semidiurna, com altura média de sizígia de $2,0 \mathrm{~m}$ e de quadratura de $0,7 \mathrm{~m}$. 0 regime de ondas responde aos ventos. As ondas de direção E-SE, associadas a ventos de mesma direção, têm altura média de 1 a 1,5 m e períodos de 5 a $7 \mathrm{~s} \mathrm{e}$ dominam ao longo do ano todo. As praias de modo geral, apresentam morfologia levemente côncava e sua inclinação varia basicamente em função da granulometria dos sedimentos que as constituem, assim como, das características do clima de onda incidente (Manso, 2003).

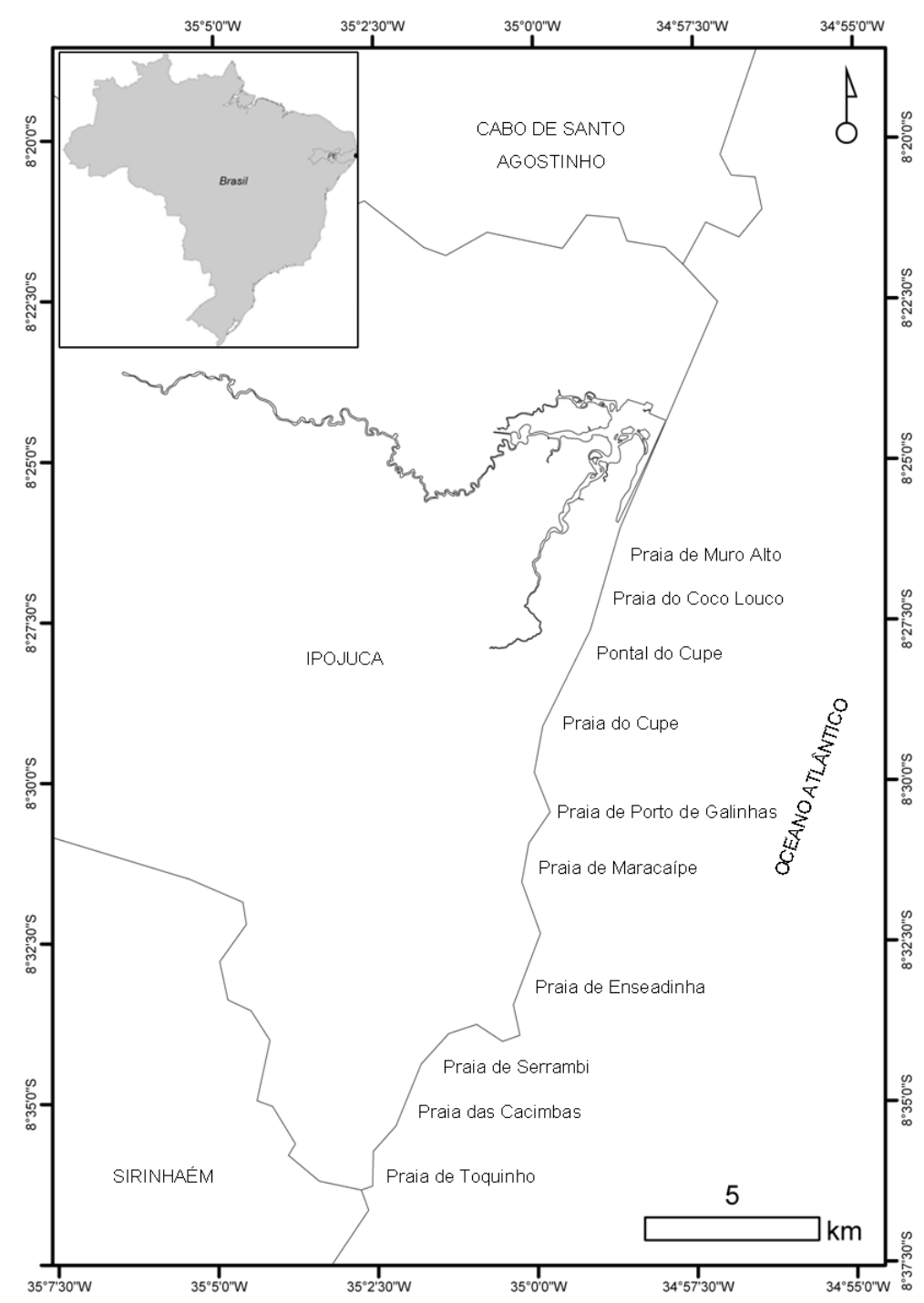

Figura 3. Localização da área de estudo e das praias analisadas. 


\subsection{Métodos}

A classificação das praias quanto aos estados morfodinâmicos, descritos na introdução, foi feita com base na análise semântica de imagens de satélite gratuitas, tendo início com o levantamento das imagens disponíveis no Google Earth para as praias de Ipojuca (Tab. 1).

As imagens foram analisadas em ambiente ArcGis 9.2 (ESRI, 2009). As observações foram complementadas por dados sobre a declividade da pós-praia e granulometria da praia (Mallmann et al., 2011). A seguir, foram identificadas feições e características que permitissem distinguir os estados morfodinâmicos, conforme Silveira et al. (2011) (Tab. 2). Adicionalmente, em função da amplitude de maré e da presença de recifes costeiros, outras feições indicadoras foram consideradas, tais como a existência de recifes em franja ou em linhas paralelas à costa, de terraços e canais de baixamar e de planícies arenosas. A ocorrência de tais feições foi analisada especialmente naquelas praias que não apresentaram feições tridimensionais.

Tabela 1. Imagens disponíveis no Google Earth para cada praia analisada.

\begin{tabular}{|c|c|c|c|}
\hline Local & Imagem & Fonte & Data \\
\hline Praia de Muro Alto & $\begin{array}{c}\text { Digital Globe } \\
\text { Digital Globe/GeoEye } \\
\text { Digital Globe/GeoEye }\end{array}$ & $\begin{array}{l}\text { Google Earth } \\
\text { Google Earth } \\
\text { Google Earth }\end{array}$ & $\begin{array}{l}25 / 08 / 2006 \\
16 / 09 / 2007 \\
05 / 11 / 2010\end{array}$ \\
\hline Praia do Coco Louco & $\begin{array}{l}\text { Digital Globe } \\
\text { Digital Globe/GeoEye } \\
\text { Digital Globe/GeoEye }\end{array}$ & $\begin{array}{l}\text { Google Earth } \\
\text { Google Earth } \\
\text { Google Earth }\end{array}$ & $\begin{array}{l}25 / 08 / 2006 \\
16 / 09 / 2007 \\
05 / 11 / 2010\end{array}$ \\
\hline Pontal do Cupe & $\begin{array}{l}\text { Digital Globe } \\
\text { GeoEye } \\
\text { GeoEye } \\
\text { GeoEye }\end{array}$ & $\begin{array}{l}\text { Google Earth } \\
\text { Google Earth } \\
\text { Google Earth } \\
\text { Google Earth }\end{array}$ & $\begin{array}{l}25 / 08 / 2006 \\
16 / 09 / 2007 \\
05 / 11 / 2010 \\
22 / 09 / 2011\end{array}$ \\
\hline Praia do Cupe & $\begin{array}{l}\text { U.S. Geological Survey/ Digital Globe } \\
\text { U.S. Geological Survey/ Digital Globe } \\
\text { U.S. Geological Survey/ Digital Globe } \\
\text { Digital Globe/GeoEye } \\
\text { Digital Globe/GeoEye } \\
\text { Digital Globe/GeoEye } \\
\text { Digital Globe/GeoEye } \\
\text { Digital Globe/GeoEye }\end{array}$ & $\begin{array}{l}\text { Google Earth } \\
\text { Google Earth } \\
\text { Google Earth } \\
\text { Google Earth } \\
\text { Google Earth } \\
\text { Google Earth } \\
\text { Google Earth } \\
\text { Google Earth }\end{array}$ & $\begin{array}{l}19 / 06 / 2006 \\
25 / 08 / 2006 \\
16 / 09 / 2007 \\
14 / 10 / 2009 \\
20 / 02 / 2010 \\
11 / 03 / 2010 \\
05 / 11 / 2010 \\
22 / 09 / 2011\end{array}$ \\
\hline Praia de Porto de Galinhas & $\begin{array}{l}\text { Digital Globe } \\
\text { Digital Globe } \\
\text { GeoEye } \\
\text { GeoEye } \\
\text { GeoEye } \\
\text { GeoEye } \\
\text { GeoEye } \\
\text { GeoEye } \\
\text { GeoEye }\end{array}$ & $\begin{array}{l}\text { Google Earth } \\
\text { Google Earth } \\
\text { Google Earth } \\
\text { Google Earth } \\
\text { Google Earth } \\
\text { Google Earth } \\
\text { Google Earth } \\
\text { Google Earth } \\
\text { Google Earth }\end{array}$ & $\begin{array}{l}19 / 06 / 2006 \\
25 / 08 / 2006 \\
31 / 08 / 2009 \\
14 / 10 / 2009 \\
20 / 02 / 2010 \\
11 / 03 / 2010 \\
13 / 04 / 2010 \\
05 / 11 / 2010 \\
22 / 09 / 2011\end{array}$ \\
\hline Praia de Maracaípe & $\begin{array}{c}\text { Digital Globe } \\
\text { Digital Globe } \\
\text { Digital Globe/GeoEye } \\
\text { Digital Globe/GeoEye } \\
\text { Digital Globe/GeoEye } \\
\text { GeoEye } \\
\text { GeoEye } \\
\text { GeoEye } \\
\text { GeoEye }\end{array}$ & $\begin{array}{l}\text { Google Earth } \\
\text { Google Earth } \\
\text { Google Earth } \\
\text { Google Earth } \\
\text { Google Earth } \\
\text { Google Earth } \\
\text { Google Earth } \\
\text { Google Earth } \\
\text { Google Earth }\end{array}$ & $\begin{array}{l}19 / 06 / 2009 \\
25 / 08 / 2006 \\
31 / 08 / 2009 \\
14 / 09 / 2009 \\
20 / 02 / 2010 \\
11 / 03 / 2010 \\
13 / 04 / 2010 \\
05 / 11 / 2010 \\
22 / 09 / 2011\end{array}$ \\
\hline Praia de Enseadinha & $\begin{array}{l}\text { Digital Globe } \\
\text { Digital Globe } \\
\text { GeoEye } \\
\text { GeoEye } \\
\text { GeoEye } \\
\text { GeoEye } \\
\text { GeoEye } \\
\text { GeoEye } \\
\text { GeoEye }\end{array}$ & $\begin{array}{l}\text { Google Earth } \\
\text { Google Earth } \\
\text { Google Earth } \\
\text { Google Earth } \\
\text { Google Earth } \\
\text { Google Earth } \\
\text { Google Earth } \\
\text { Google Earth } \\
\text { Google Earth }\end{array}$ & $\begin{array}{l}19 / 06 / 2006 \\
25 / 08 / 2006 \\
31 / 08 / 2009 \\
14 / 10 / 2009 \\
20 / 02 / 2010 \\
11 / 03 / 2010 \\
13 / 04 / 2010 \\
05 / 11 / 2010 \\
22 / 09 / 2011\end{array}$ \\
\hline Praia das Cacimbas & $\begin{array}{c}\text { Digital Globe } \\
\text { Digital Globe } \\
\text { Digital Globe/ GeoEye } \\
\text { GeoEye } \\
\text { GeoEye }\end{array}$ & $\begin{array}{l}\text { Google Earth } \\
\text { Google Earth } \\
\text { Google Earth } \\
\text { Google Earth } \\
\text { Google Earth }\end{array}$ & $\begin{array}{l}19 / 06 / 2006 \\
25 / 08 / 2009 \\
31 / 08 / 2009 \\
11 / 03 / 2010 \\
13 / 04 / 2010\end{array}$ \\
\hline Praia de Serrambi & $\begin{array}{c}\text { Digital Globe/ MapLink TeleAtlas } \\
\text { Digital Globe/ MapLink TeleAtlas } \\
\text { GeoEye } \\
\text { GeoEye/ MapLink TeleAtlas } \\
\text { GeoEye/ MapLink TeleAtlas } \\
\text { GeoEye/ MapLink TeleAtlas } \\
\text { GeoEye/ MapLink TeleAtlas } \\
\text { GeoEye/ MapLink TeleAtlas }\end{array}$ & $\begin{array}{l}\text { Google Earth } \\
\text { Google Earth } \\
\text { Google Earth } \\
\text { Google Earth } \\
\text { Google Earth } \\
\text { Google Earth } \\
\text { Google Earth } \\
\text { Google Earth }\end{array}$ & $\begin{array}{l}19 / 06 / 2006 \\
25 / 08 / 2006 \\
31 / 08 / 2009 \\
14 / 10 / 2009 \\
20 / 02 / 2010 \\
11 / 03 / 2010 \\
13 / 04 / 2010 \\
22 / 09 / 2011\end{array}$ \\
\hline Praia de Toquinho & $\begin{array}{c}\text { U.S. Geological Survey/ Digital Globe } \\
\text { Digital Globe/ MapLink TeleAtlas } \\
\text { Digital Globe/GeoEye }\end{array}$ & $\begin{array}{l}\text { Google Earth } \\
\text { Google Earth } \\
\text { Google Earth }\end{array}$ & $\begin{array}{l}25 / 07 / 2003 \\
19 / 06 / 2006 \\
11 / 03 / 2010\end{array}$ \\
\hline
\end{tabular}


Tabela 2. Indicadores utilizados para a classificação morfodinâmica de praias dominadas por ondas (Silveira et al., 2011).

\begin{tabular}{|c|c|c|}
\hline Estado morfodinâmico & Feições indicadoras & Observações \\
\hline \multirow{3}{*}{ Dissipativo } & Zonas de surfe extensa (OI) & $\begin{array}{l}\text { Largura de zona de surfe superior a } \\
\qquad 100 \mathrm{~m}\end{array}$ \\
\hline & Zona de espraiamento extensa (OI) & $\begin{array}{l}\text { Largura superior a } 10 \mathrm{~m} \text {, indicando } \\
\text { baixa declividade da praia }\end{array}$ \\
\hline & & $\begin{array}{l}\text { Baixa declividade indica alto grau de } \\
\text { dissipação da energia na zona de surfe }\end{array}$ \\
\hline \multirow{3}{*}{ Intermediário } & Cúspide e/ou Mega-Cúspide (OI) & $\begin{array}{l}\text { Feições rítmicas na linha de costa de } \\
\text { pequena }(<100 \mathrm{~m}) \text { e grande }(>100 \mathrm{~m}) \\
\text { escalas, respectivamente }\end{array}$ \\
\hline & Corrente de Retorno (OI) & $\begin{array}{l}\text { Observada pela tonalidade da água } \\
\text { próximo à zona de arrebentação. } \\
\text { Devido à sua alta capacidade de } \\
\text { transporte, sua presença é associada } \\
\text { à tonalidade similar à dos sedimentos } \\
\text { da praia, indicando a presença de } \\
\text { sedimentos em suspensão }\end{array}$ \\
\hline & Zona de Espraiamento Curta (OI) & $\begin{array}{l}\text { Largura entre } 5 \text { e } 10 \mathrm{~m} \text {, indicando } \\
\text { declividade moderada }\end{array}$ \\
\hline \multirow[t]{3}{*}{ Refletivo } & $\begin{array}{l}\text { Quebra de ondas na base da zona de } \\
\text { espraiamento (OI) }\end{array}$ & $\begin{array}{l}\text { Como esse tipo de praia não apresenta } \\
\text { bancos, a quebra de ondas só } \\
\text { ocorre nas proximidades da zona de } \\
\text { espraiamento, que é estreita devido à } \\
\text { alta declividade da face praial }\end{array}$ \\
\hline & & $\begin{array}{c}\text { Feição rítmica na linha de costa com } \\
\text { pequena escala }(<100 \mathrm{~m})\end{array}$ \\
\hline & Cúspide (OI) & \\
\hline
\end{tabular}

Silveira et al. (2011) lembram que a metodologia utilizada apresenta limitações. A interpretação de imagens requer que seja possível observar e distinguir feições que caracterizam cada estágio morfodinâmico. Isso faz com que resultados obtidos sejam influenciados pela resolução e qualidade das imagens, incluindo cobertura de nuvens, luminosidade, transparência da água e condições de ondas no momento do imageamento. Tais fatores interferem principalmente na interpretação de feições submersas, como bancos, já que esses podem se tornar invisíveis em condições de ondas muito pequenas e/ou águas muito turvas. Para minimizar os erros de classificação, os autores sugerem que a classificação do estado morfodinâmico das praias deve considerar a identificação e interpretação do maior número de feições possíveis.

\section{Resultados}

Foi possível reconhecer dez entre os quinze estágios morfodinâmicos descritos, os quais são apresentados por praia, conforme segue. 


\subsection{Muro Alto}

Muro Alto tem aproximados 3,8 km de extensão e apresenta particularidades que tornam complexa a análise do seu estado morfodinâmico, uma vez que se situa junto a um estuário (Rio Ipojuca) e é bastante protegida da ação de ondas pela presença de um corpo recifal arenítico emerso próximo e paralelo à praia na porção norte e soldado à praia, se comportando como um recife em franja, na porção sul. A praia é abrigada e apresenta sinuosidade, porém, não são observadas feições tridimensionais. 0 perfil praial apresenta baixa declividade $\left(<5^{\circ}\right)$ e a granulometria é composta por areia média a fina (Mallmann et al., 2011).

Na porção norte, mais abrigada, a onda parece quebrar ou refletir em uma única linha, contra o recife, tendo a energia refletida ou dissipada (Fig. 4A). Não são detectadas variações consideráveis entre as imagens observadas. 0 estágio predominante se assemelha àquele descrito como praias bordejadas por recifes de coral (B+coral reef), estando de acordo com o modelo no que se refere à quebra de ondas ao longo do ciclo de maré, além da semelhança geomorfológica. Cabe observar que não se trata de um recife de coral em franja e sim de um recife arenítico destacado e posicionado paralelamente à praia. É possível observar uma pós-praia estreita $(<20 \mathrm{~m})$, que não recebe diretamente a energia das ondas ao longo do ciclo de maré, o qual apenas parece variar o nível d'água, cujo fundo apresenta formas típicas (sandwaves) (Fig. 4B). Tais características se estendem ao longo de aproximados $2,4 \mathrm{~km}$ de linha de costa, na porção norte da praia.

Na porção sul, ao longo de $1,4 \mathrm{~km}$, o recife se encontra soldado à praia. Assim como previsto para o modelo de praias bordejadas por recifes de franja (BCR), embora as imagens analisadas tenham sido tomadas em momentos de maré baixa, é possível observar que durante a maré alta, uma estreita praia fica exposta. As ondas dissipam energia sobre o recife e atingem a face praial, que apresenta cúspides localizadas apenas no extremo sul do segmento. Durante a baixamar, as ondas quebram na borda externa do recife, o qual fica exposto. Aparentemente, em toda a extensão da praia há um controle mais geomorfológico dos processos que determinam a tipologia e, consequentemente, o estágio morfodinâmico, em detrimento da ação de ondas e marés.

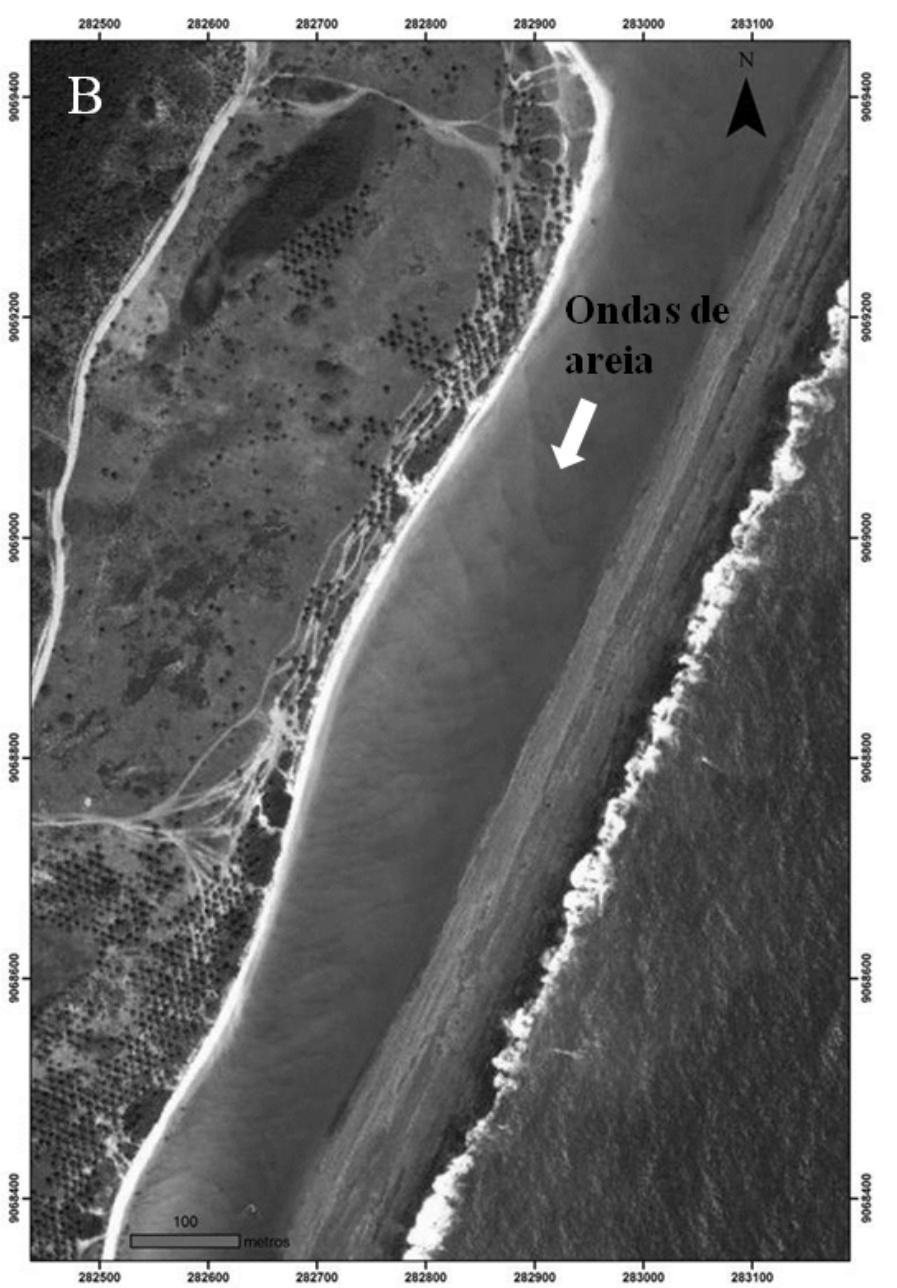

Figura 4. Praia de Muro Alto, onde se destacam: A) norte da Praia, abrigada por um recife arenítico sobre o qual a onda reflete/quebra em uma única linha, conforme mostram as setas (25/08/2006); B) ondas de areia - indicadas pela seta - formadas na porção abrigada pelo recife (05/11/2010). Fuso de referência: 25S. Fonte: Google Earth. 


\subsection{Praia do Coco Louco}

Com moderado/alto grau de exposição à energia de ondas e marés, esta praia se estende ao longo de aproximadamente $1,1 \mathrm{~km}$. Para os momentos analisados, é possível observar que a morfodinâmica é determinada essencialmente pela energia de ondas, uma vez que estão presentes feições tridimensionais. Na imagem de 25/08/2006 (Fig. 5A), estão presentes correntes de retorno e bancos transversais e, embora se perceba alguma influência da maré, é nítido o domínio da energia de ondas no estabelecimento do estágio morfodinâmico, o qual pode ser descrito como bancos transversais e correntes de retorno (TBR). A imagem seguinte (16/09/2007) (Fig. 5B) mostra uma praia com características transicionais entre TBR e banco e praia rítmicos (RBB), na qual são observadas correntes de retorno transversais, mas também ritmicidade nos bancos e na praia. Já em 05/11/2010 (Fig. 5C), há grande turbulência na zona de arrebentação, indicando a presença de correntes de retorno. A praia cuspatada, assim como o banco e a zona de espraiamento, apontam para a ocorrência do estágio RBB.
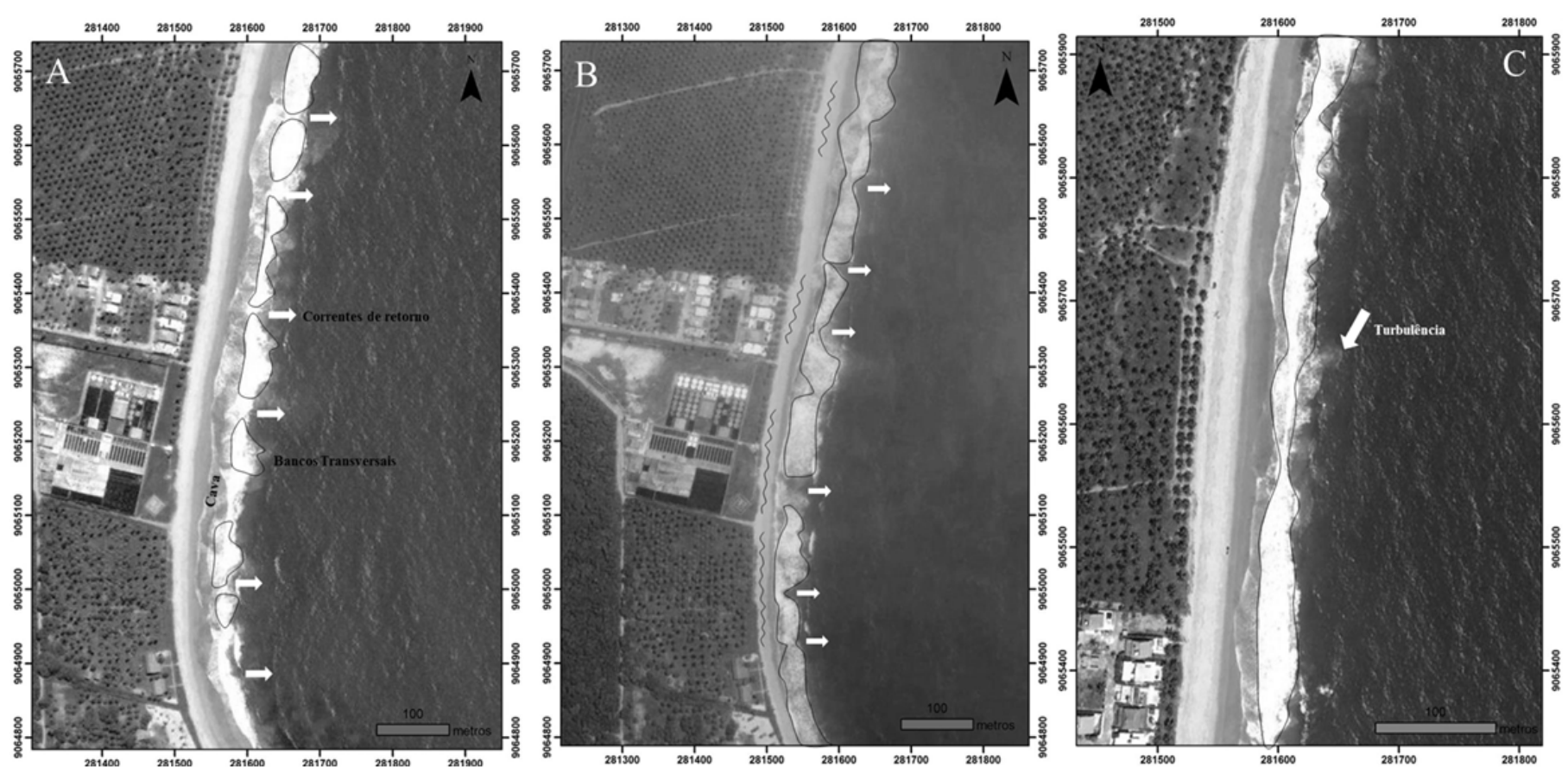

Figura 5. Praia do Coco Louco, onde se destacam: A) Estágio morfodinâmico banco transversal e correntes de retorno (estas indicadas pelas setas) (TBR) (25/08/2006); B) características transicionais entre TBR e banco e praia rítmicos (setas indicando a localização das correntes de retorno) (RBB) (16/09/2007); C) características rítmicas (setas indicam área de turbulência) (05/11/2010). Fuso de referência: 25S. Fonte: Google Earth.

\subsection{Pontal do Cupe}

0 ponto de inflexão na linha de costa que marca o limite entre as praias de Coco Louco e Cupe consiste em um pontal com extensão aproximada de $1 \mathrm{~km}$. Trata-se de uma praia bordejada por um recife em franja de profundidade variável que atenua a energia de onda incidente na costa. Foram analisadas quatro imagens, duas aparentemente durante a preamar e as outras duas durante a baixamar.

Apesar da influência do corpo recifal sobre sua morfologia, a praia pode ser classificada como "modificada pela maré", uma vez que, mais do que dominar o controle sobre os estágios morfodinâmicos, a estrutura atenua a energia de ondas, reduzindo sua importância e amplificando a importância relativa da maré. Não ocorrem feições tridimensionais e as ondas incidem numa estreita porção da face após serem parcialmente dissipadas sobre o recife durante a preamar (Fig. 6A). Já durante a baixamar, a praia adquire características de terraço, apresentando, apenas na imagem de $05 / 11 / 2010$, canais através dos quais a água retorna (rips) e caracterizando o estágio morfodinâmico descrito como praia refletiva e canais de baixamar (R+LT rips) (Fig. 6B). 

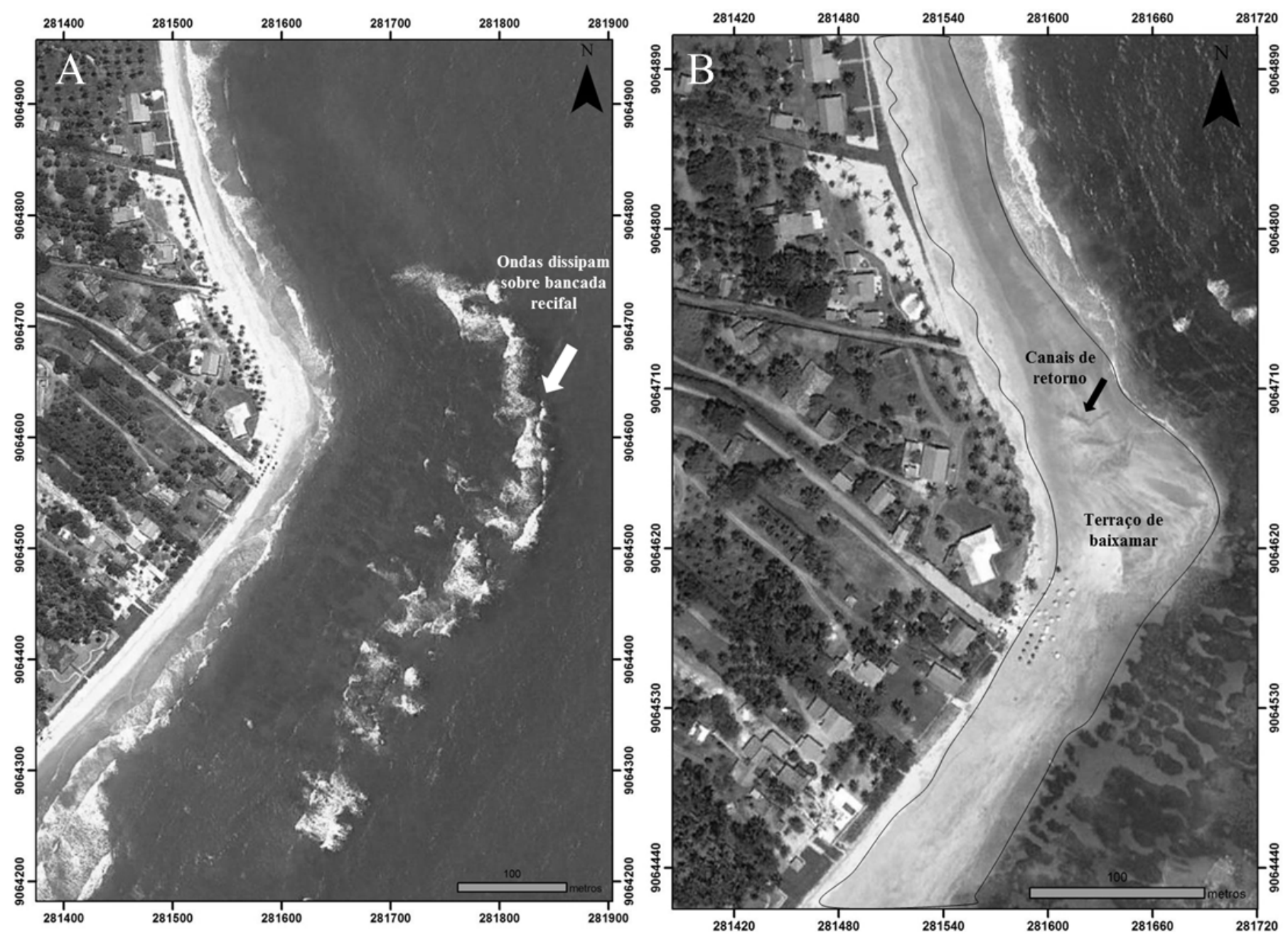

Figura 6. Pontal do Cupe, onde se destacam: A) ondas incidindo na praia após dissipação parcial da energia junto ao recife durante a premar, conforme indica a seta (22/09/2011); B) terraço de baixamar com canais de retorno (indicados pela seta) (05/11/2010). Fuso de referência: 25S. Fonte: Google Earth.

\subsection{Cupe}

A Praia do Cupe $(\sim 5 \mathrm{~km})$ apresenta alto grau de exposição à energia de ondas. 0 perfil praial é íngreme, com declividade superior a $5^{\circ}$ e a granulometria é composta por areia média (Mallmann et al., 2011). A arrebentação é predominantemente mergulhante e a praia apresenta uma dinâmica intensa, o que reflete na mudança dos estados morfodinâmicos. Para esta praia foram analisadas sete imagens, que mostram características típicas dos estágios intermediários. Entretanto, particularidades da análise multitemporal requerem maior detalhamento, inclusive no que se refere à ocorrência de estágios transicionais e de gradações - variações das características ao longo da praia - conforme resumido na tabela 3 e descrito a seguir.

Tabela 3. Resumo das características observadas para a Praia do Cupe.

\begin{tabular}{ccccccc}
\hline Data & $\begin{array}{c}\text { Estágio } \\
\text { maré }\end{array}$ & Bancos/Terraço & Feições na praia & $\begin{array}{c}\text { Correntes } \\
\text { de Retorno }\end{array}$ & $\begin{array}{c}\text { Gradação } \\
\text { ao longo } \\
\text { da praia }\end{array}$ & $\begin{array}{c}\text { Classificação } \\
\text { (Norte-Sul) }\end{array}$ \\
\hline $19 / 06 / 06$ & $+\mathrm{BM}$ & Rítmicos & Cúspides & Presentes & Ausente & RBB \\
$25 / 08 / 06$ & $+\mathrm{PM}$ & Transversais & Megacúspides & Presentes & Presente & TBR/R \\
$16 / 09 / 07$ & + PM & Rítmicos/Transversais & Megacúspides & Presentes & Presente & RBB/TBR/R \\
$14 / 10 / 09$ & $+\mathrm{BM}$ & Transversais & Megacúspides & Presentes & Presente & TBR/LTT \\
$20 / 02 / 10$ & $+\mathrm{BM}$ & Rítmicos & Cúspides & Presentes & Presente & RBB/T \\
$11 / 03 / 10$ & $+\mathrm{BM}$ & Terraço & Cúspides & Presentes & Ausente & LTT \\
$13 / 04 / 10$ & $+\mathrm{BM}$ & Rítmicos/Transversais/Terraço & Cúspides & Presentes & Ausente & LTT \\
$05 / 11 / 10$ & $+\mathrm{BM}$ & Transversais/Terraço & Cúspides e & Presentes & Presente & TBR/LTT \\
$22 / 09 / 11$ & $+\mathrm{PM}$ & Tranversais/Rítmicos/Terraço & Megacúspides & Presentes & Presente & RBB/TBR/LTT \\
\hline
\end{tabular}


A imagem de 19/06/2006 mostra zona de arrebentação bem marcada, com presença de bancos rítmicos que se estendem por toda a praia (Fig. 7A). Correntes de retorno conferem maior ritmicidade à praia, permitindo classificá-la segundo o estágio banco e praia rítmicos (RBB). A zona de surfe apresenta largura entre 100 e $200 \mathrm{~m}$ e cúspides são perceptíveis.

Em 25/08/2006, o fluxo está segregado lateralmente, com correntes de retorno isoladas e bancos transversais soldados à praia, caracterizando o estado banco transversal corrente de retorno e (TBR). Junto à praia ocorrem megacúspides ou baías. No extremo sul, a praia apresenta gradação e adquire características refletivas (R).

Na imagem de 16/09/2007, é possível verificar correntes de retorno e ampla zona de surfe $(140 \mathrm{~m})$. A praia apresenta características transicionais. Ocorrem baías e os bancos se aproximam e se soldam à praia na porção sul, onde predominam características do estágio banco transversal e corrente de retorno (TBR). A norte, uma cava se faz presente entre banco e praia rítmicos, caracterizando este estágio (RBB). Na extremidade sul, as características são refletivas (R).

Em 14/10/2009, a zona de surfe permanece ampla $(>100 \mathrm{~m})$ e a praia apresenta características do

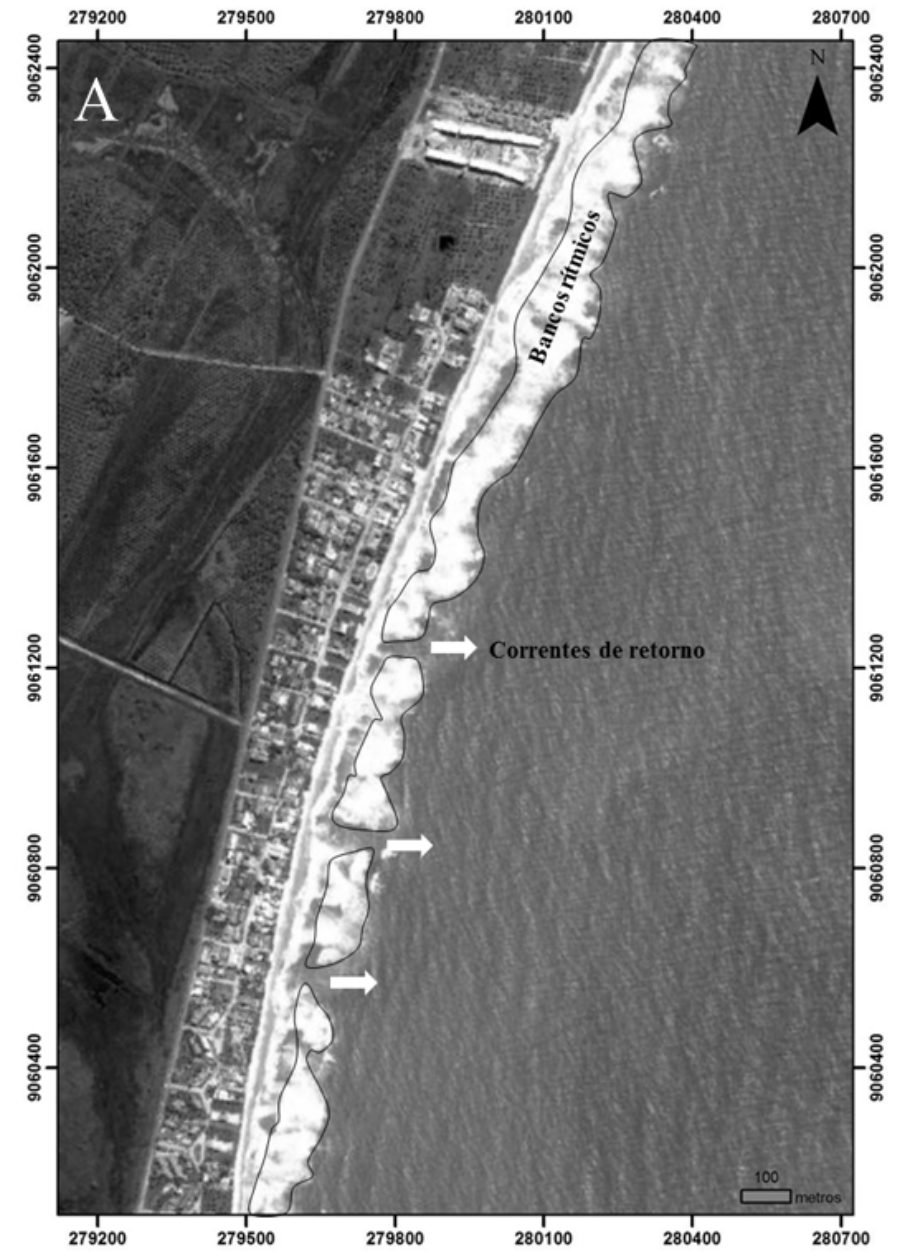

estado banco transversal e corrente de retorno (TBR), mostrando bancos soldados. Megacúspides, embora presentes, são menos pronunciadas. A sul observa-se uma pequena extensão com características do estado terraço de baixamar (LTT).

Na imagem de 20/02/2010, a arrebentação parece quase contínua, sendo interrompida por correntes de retorno que não chegam a segregar o fluxo lateralmente. Feições rítmicas podem ser observadas, com cúspides mais visíveis - com comprimento de onda em torno de 20-30 m - e presença de praia e bancos rítmicos, caracterizando o estado RBB. A sul ocorre uma gradação e a praia adquire características transicionais (na tabela, abreviado como " $\mathrm{T}$ ").

Em 11/03/2010, a praia apresenta características de terraço de baixamar e cúspides estão presentes ao longo de toda sua extensão. São observadas correntes de retorno menos definidas devido à presença de plumas de sedimentos e vórtices na zona de surfe, assim como na imagem de 20/02/2010. Nela, no entanto, cúspides não estão presentes e ocorrem bancos rítmicos e transversais. Sobre o terraço, especialmente a sul, é possível observar pequenas correntes de retorno.

A imagem de 05/11/2010 é a mais característica

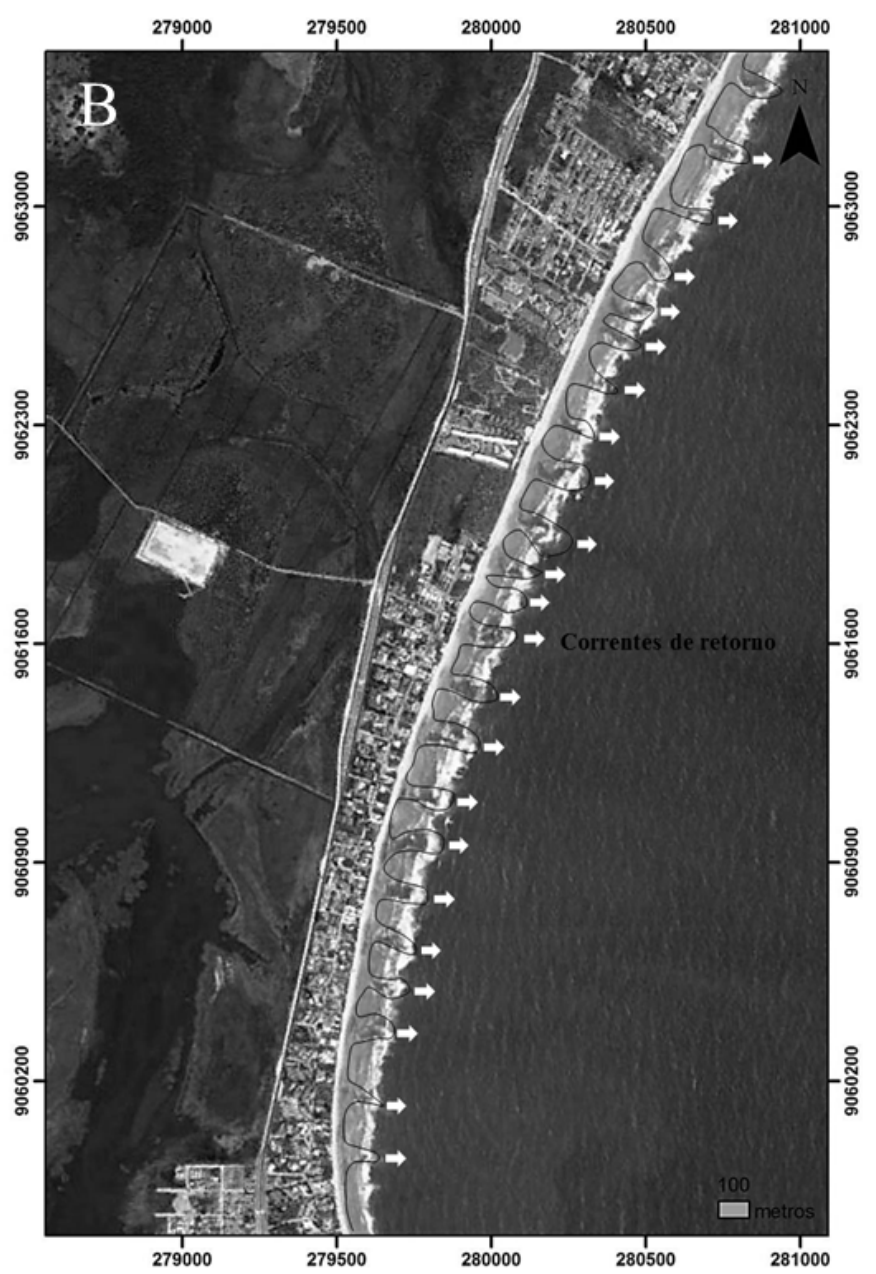

Figura 7. Praia do Cupe, onde se destacam: A) feições rítmicas (19/06/2006); B) momento característico do estágio banco transversal e corrente de retorno (TBR) - em ambas as imagens, as setas indicam correntes de retorno (05/11/2010). Fuso de referência: $25 \mathrm{~S}$. Fonte: Google Earth. 
do estado banco transversal e corrente de retorno (TBR) (Fig. 7B). Correntes de retorno estão presentes ao longo da extensão do segmento e é visível a segregação lateral do fluxo. 0 espaçamento entre as mesmas varia entre $80 \mathrm{~m}$ e $230 \mathrm{~m}$ (média de $145 \pm 45 \mathrm{~m}$ ). A sul, com a praia rítimica, é possível identificar o afloramento de recifes areníticos junto aos embaiamentos em função do processo erosivo pontual. No extremo sul ocorrem características típicas de terraço de baixamar (LTT).

Em 22/09/2011, a praia assemelha-se àquela da imagem anterior, com características típicas de banco transversal e corrente de retorno (TBR) a sul e transicionais para banco e praia rítmicos (RBB) mais a norte. Correntes de retorno e megacúspides são visíveis. $\mathrm{Na}$ extremidade sul, permanecem características de terraço de baixamar (LTT).

\subsection{Porto de Galinhas}

Porto de Galinhas $(\sim 1 \mathrm{~km})$ constitui uma praia arenosa parcialmente abrigada, semi-protegida por recifes biogênicos similares a um recife em franja a uma distância que varia de menos de $100 \mathrm{~m}$ (sul) a cerca de $200 \mathrm{~m}$ (norte). 0 corpo recifal apresenta largura variável, chegando a $330 \mathrm{~m}$. Trata-se de uma estrutura semi-submersa que dissipa grande parte da energia de ondas. Tal particularidade confere à praia de Porto de Galinhas uma configuração saliente e um perfil suave e de granulometria fina (Mallmann et al., 2011).

Devido ao seu posicionamento, na zona de sombra de um corpo recifal, a praia não apresenta grandes alterações sob o ponto de vista morfodinâmico. Maiores variações são observadas em função do ciclo de maré, como em 19/06/2006 (Fig. 8A). Na ocasião, a maré alta deixa visível uma estreita faixa de praia e a arrebentação se dá essencialmente sobre o corpo recifal e, posteriormente, concentrada junto à face praial. Tais características estão em consonância com o previsto para praias associadas a recifes em franja durante a preamar e são vistas ainda na imagem de 20/02/2010. Nas demais imagens, tomadas próximo a momentos de baixamar, a praia também se enquadra na descrição de Short (2006) para praias bordejadas por recifes em franja. Características deste modelo incluem uma praia estreita $(<50 \mathrm{~m})$, atingida pelas ondas durante a preamar, de maneira insuficientemente incisiva para que sejam produzidas feições tridimensionais (Fig. 8B).
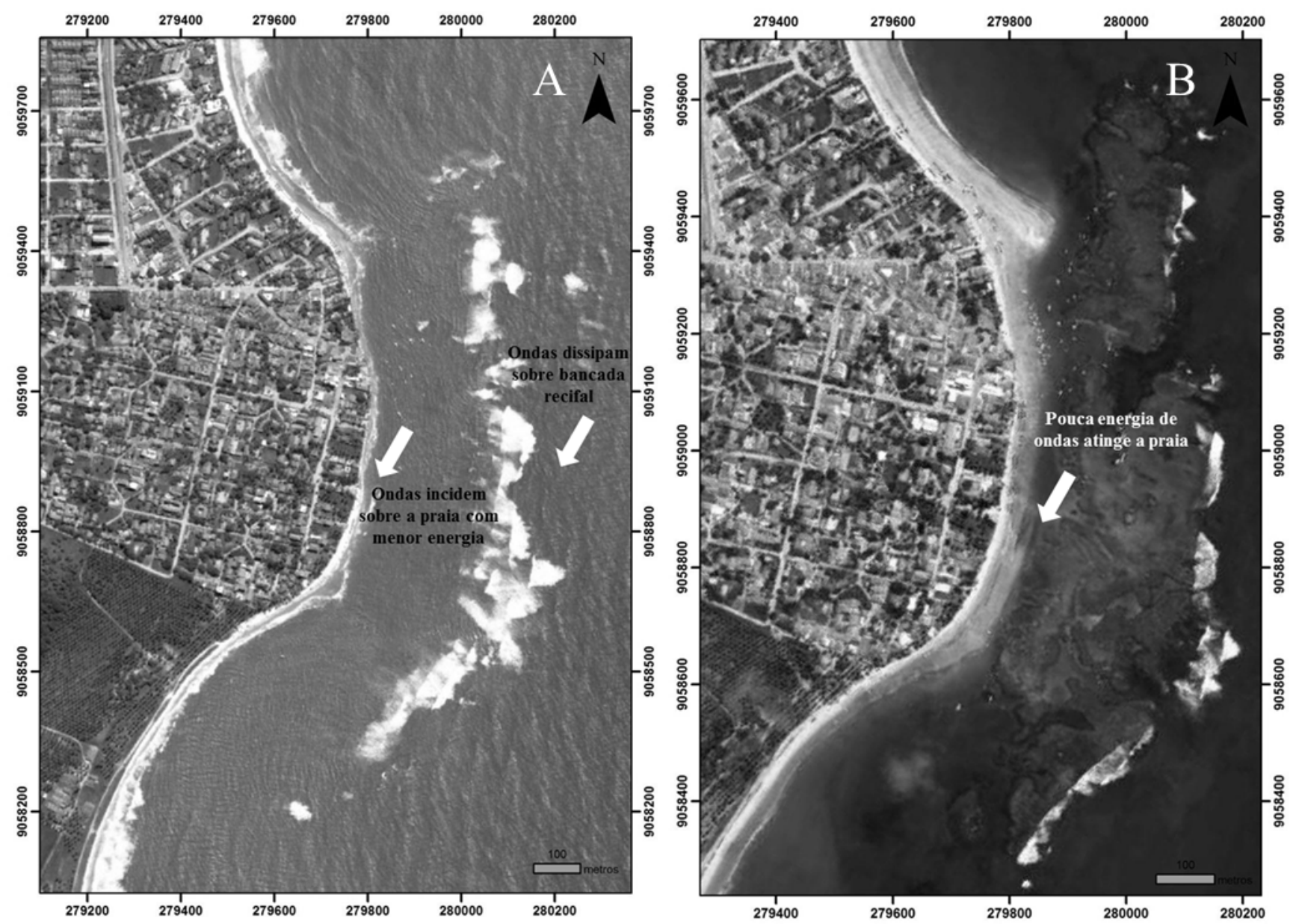

Figura 8. Praia de Porto de Galinhas durante os estágios de maré: A) preamar, com grande parte da energia de ondas sendo dissipada sobre o recife e estreita faixa de areia, conforme indicado pelas setas (19/06/2006); B) baixamar, com pouca energia chegando à costa (indicado pela seta) (13/04/2010). Fuso de referência: 25S. Fonte: Google Earth. 


\subsection{Maracaípe}

Foram analisadas nove imagens da Praia de Maracaípe, a qual apresenta configuração em forma de arco, com certa concavidade. Trata-se de uma praia exposta, com pendente íngreme $\left(>5^{\circ}\right)$ e areia predominantemente grossa, na qual as ondas arrebentam de forma mergulhante. A ausência de recifes confere à praia uma dinâmica intensa (Tab. 4). Ademais, ocorre uma gradação ao longo do arco praial uma vez que na porção norte ( 0,3 km) a praia recebe influência do segmento adjacente, protegido por recifes (ver figuras 8A e 8B). Tal gradação ocorre, ainda, porque longe da porção central, mais exposta à energia das ondas ( 2,4 km), a maré passa a atuar mais, tornando a praia mais bidimensional na sua porção sul ( 0,5 km). Em contrapartida, nas porções centrais, onde as ondas incidem de forma mais direta, ocorrem feições tridimensionais típicas dos estágios intermediário, além de maiores variações.

A porção norte não apresenta feições tridimensionais, indicando que há um domínio da maré, cujo ciclo determina variações observadas. Este setor se assemelha ao estágio praia e planície arenosa ( $\mathrm{B}+$ sand flat $)$, típico de praias dominadas pela maré. Características do estágio incluem praia estreita, de baixa energia e baixo gradiente durante a preamar, associada a uma planície arenosa e sem feições aparentes durante a baixamar. Já o extremo sul da praia apresenta características de terraço de baixamar (LTT), no qual, durante a preamar, as ondas incidem atenuadas sobre a face praial, que apresenta cúspides. Na baixamar, um amplo terraço desprovido de feições fica exposto. Em determinados momentos, são observadas ravinas de escoamento com espaçamento inferior a $20 \mathrm{~m}$. Para a porção central do arco, as observações são descritas a seguir.

Em 19/06/2006, a incidência de ondas ocorre paralelamente à linha de costa e há setores com características bem definidas ao longo do arco praial, representados pelos extremos norte e sul e pela porção central. Na maior parte do segmento, ocorrem feições típicas do estado banco e praia rítmicos (RBB) no qual é possível observar um banco longitudinal não soldado à praia e segmentado por correntes de retorno (Fig. 9A), o que confere ao mesmo um aspecto sinuoso. A zona de surfe apresenta largura entre 40 e $100 \mathrm{~m}$.
Em 25/08/2006 alguns bancos já estão soldados à praia, o que caracteriza o estágio banco transversal e corrente de retorno (TBR). No entanto, não há grande segregação do fluxo e a zona de surfe está concentrada junto à face praial, sugerindo um estágio transicional entre esse e o banco e praia rítmicos (RBB).

Na imagem de 31/08/2009, a zona de surfe está reduzida (< $50 \mathrm{~m}$ de largura) e a arrebentação se dá próximo à face praial, como é típico de praias refletivas. Correntes de retorno estão presentes e são visíveis pela pluma de sedimentos e vórtices. Os bancos seguem soldados à praia, sugerindo transição entre os estágios banco transversal e corrente de retorno (TBR) e terraço de baixamar (LTT).

Em 14/10/2009, a praia apresenta características do estágio banco e praia rítmicos (RBB), como a presença de bancos rítmicos separados da praia por uma cava sinuosa.

Na imagem de 20/02/2010, o estágio predominante é o banco e praia rítmicos (RBB), com cúspides evidentes (dimensões entre 20-30 m).

Em 11/03/2010 a praia apresenta características predominantes do estado banco e cava longitudinais (LBT), embora ainda com características de RBB, como a cava pouco sinuosa separando o banco da praia. Podem ser observadas cúspides ao longo do arco (Fig. 9B), cujas dimensões diminuem gradativamente de norte para sul (de $\sim 30 \mathrm{~m}$ para $\sim 15 \mathrm{~m}$ ). Correntes de retorno são observadas pelas plumas de sedimento perpendiculares à costa.

$\mathrm{Na}$ imagem de 13/04/2010, os bancos na maior parte do segmento já estão soldados à praia, caracterizando um estado TBR transicional para LTT.

Em 22/09/2011 a praia adquire características refletivas, com poucas correntes de retorno. A zona de surfe é estreita $(<50 \mathrm{~m}$ ) e concentrada junto à praia.

A ocorrência de feições tridimensionais evidencia o domínio das ondas no estabelecimento da morfologia e dos estágios morfodinâmicos da praia, sobretudo na porção central. Cúspides ou megacúspides (ou a ocorrência simultânea de ambas), bem como correntes de retorno são observadas em $67 \%$ das imagens. Por sua vez, bancos (transversais ou rítmicos) ocorrem em 89\% das imagens analisadas.

Tabela 4. Resumo das características observadas para a Praia de Maracaípe.

\begin{tabular}{|c|c|c|c|c|c|c|}
\hline Data & $\begin{array}{l}\text { Estágio } \\
\text { maré }\end{array}$ & Bancos/Terraço & Feições na praia & $\begin{array}{c}\text { Correntes de } \\
\text { Retorno } \\
\end{array}$ & Gradação & $\begin{array}{c}\text { Classificação } \\
\text { (Norte-Sul) }\end{array}$ \\
\hline $19 / 06 / 06$ & $+\mathrm{PM}$ & Rítmicos & Cúspides & Presentes & Presente & $\mathrm{B}+$ sand flat /RBB/LTT \\
\hline $25 / 08 / 06$ & $+\mathrm{PM}$ & Transversais & Ausentes & Ausentes & Presente & $\mathrm{B}+$ sand flat /TBR-RBB/LTT \\
\hline $31 / 08 / 09$ & $+\mathrm{BM}$ & Transversais/Terraço & Ausentes & Presentes & Presente & $\mathrm{B}+$ sand flat /TBR - LTT/LTT \\
\hline $14 / 10 / 09$ & $+\mathrm{PM}$ & Rítmicos & Ausentes & Ausentes & Presente & $\mathrm{B}+$ sand flat /RBB/LTT \\
\hline $20 / 02 / 10$ & $+\mathrm{PM}$ & Rítmicos & Cúspides & Presentes & Presente & $\mathrm{B}+$ sand flat /RBB/LTT \\
\hline $11 / 03 / 10$ & $+\mathrm{BM}$ & Rítmicos/Transversais/Terraço & Cúspides & Presentes & Presente & $\mathrm{B}+$ sand flat /RBB-LBT/LTT \\
\hline $13 / 04 / 10$ & $+\mathrm{BM}$ & Transversais/Terraço & Cúspides & Presentes & Presente & $\mathrm{B}+$ sand flat /TBR-LTT/LTT \\
\hline $05 / 11 / 10$ & $+\mathrm{BM}$ & Transversais/Terraço & Cúspides & Presentes & Presente & $\mathrm{B}+$ sand flat /TBR/LTT \\
\hline $22 / 09 / 11$ & $+\mathrm{PM}$ & Ausentes & Cúspides/Megacúspides & Ausente & Presente & $\mathrm{B}+$ sand flat / LTT \\
\hline
\end{tabular}



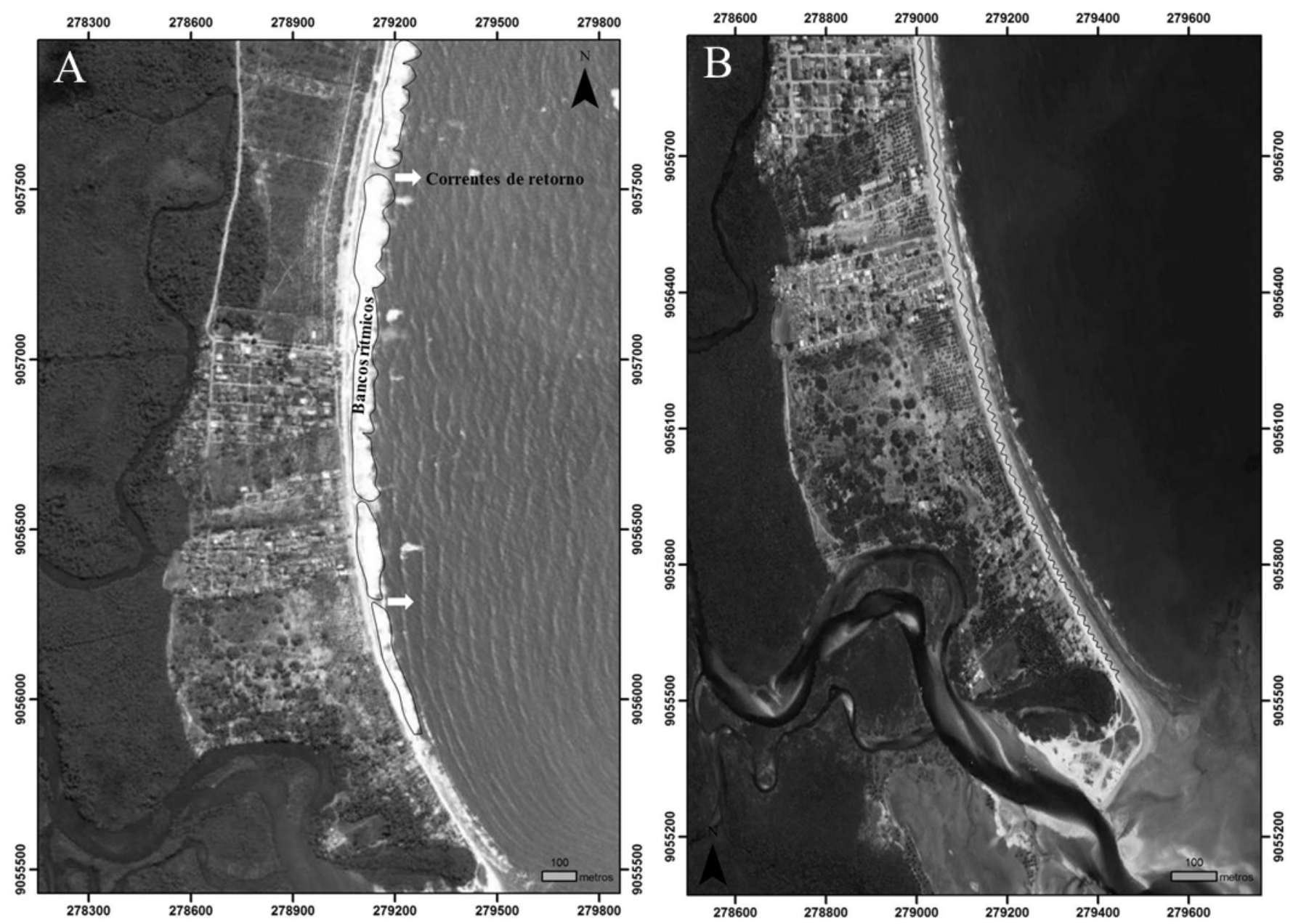

Figura 9. Praia de Maracaípe, com destaque para: A) presença de um banco longitudinal não soldado à praia e segmentado por correntes de retorno (indicadas pelas setas) (19/06/2006); B) cúspides ao longo do arco praial (11/03/2010). Fuso de referência: 25S. Fonte: Google Earth.

\subsection{Enseadinha}

A Praia de Enseadinha tem 2,5 km de extensão e é parcialmente protegida da incidência de ondas por recifes cuja distância até a costa varia desde poucos metros até aproximados 500m. Esta particularidade forma uma praia diversa sob o ponto de vista morfológico, que pode ser assim setorizada: a norte, uma porção retilínea; no centro, um embaiamento e a sul, um segmento retilíneo localizado na inflexão do Pontal de Serrambi. A análise das imagens mostra que durante a baixamar dominam processos de maré, e na preamar aumenta a importância relativa das ondas, embora a praia permaneça sob influência da maré. A seguir são descritas as características observadas nas imagens, conforme síntese na tabela 5 .

A imagem de 19/06/2006 mostra uma zona de arrebentação concentrada sobre os recifes, onde a energia de ondas é atenuada. Tal arrebentação tem largura variável e apresenta descontinuidades. Junto à face praial é possível observar outra linha de arrebentação, cujas características variam de acordo com os três setores supracitados. A sul, a mesma se apresenta estreita $(\sim 20 \mathrm{~m})$ e junto à praia é possível observar cúspides. O estado morfodinâmico predominante parece ser refletivo e terraço de baixamar (R+LTT), típico de praias modificadas pela maré.

Nas demais imagens, a praia apresenta características do estágio praia e planície de maré arenosa, típicas de costas dominadas pela maré. Em 25/08/2006, a praia adquire características típicas deste estágio e é possível observar a baixa energia de ondas e a presença de um terraço soldado à praia, cuja largura, variável, é da ordem de dezenas de metros (Fig. 10). 0 afloramento do lençol freático, sob a forma de ravinas, ocorre nas imagens datadas de 31/08/2009, 14/10/2009, 13/04/2010 e 05/11/2010. É possível afirmar que esta praia, marcada pela bidimensionalidade, apresenta predominantemente características de domínio mareal, nas quais predomina o estágio Praia+planície de maré arenosa (89\% das imagens analisadas). 
Tabela 5. Resumo das características observadas para a Praia de Enseadinha.

\begin{tabular}{|c|c|c|c|c|c|c|}
\hline Data & $\begin{array}{c}\text { Estágio } \\
\text { maré }\end{array}$ & Bancos/Terraço & Feições na praia & Correntes de Retorno & Gradação & $\begin{array}{c}\text { Classificação } \\
\text { (Norte-Sul) }\end{array}$ \\
\hline 19/06/06 & $+\mathrm{PM}$ & Transversais/Rítmicos & Cúspides & Presentes & Presente & R+LTT \\
\hline $25 / 08 / 06$ & $+\mathrm{BM}$ & Terraço & Cúspides/Mini rips & Ausentes & Ausente & $\mathrm{B}+$ tidal flats \\
\hline 31/08/09 & $+\mathrm{BM}$ & Terraço & Mini rips & Ausentes & Ausente & $\mathrm{B}+$ tidal flats \\
\hline $14 / 10 / 09$ & $+\mathrm{BM}$ & Terraço & Mini rips & Ausentes & Ausente & $\mathrm{B}+$ tidal flats \\
\hline $11 / 03 / 10$ & $+\mathrm{BM}$ & Terraço & Cúspides/Mini rips & Ausentes & Ausente & $\mathrm{B}+$ tidal flats \\
\hline $20 / 02 / 10$ & $+\mathrm{BM}$ & Terraço & Ausentes & Ausentes & Ausente & $\mathrm{B}+$ tidal flats \\
\hline $13 / 04 / 10$ & $+\mathrm{BM}$ & Terraço & Cúspides/Mini rips & Ausentes & Ausente & $\mathrm{B}+$ tidal flats \\
\hline 05/11/10 & $+\mathrm{BM}$ & Terraço & Mini rips & Ausentes & Ausente & $\mathrm{B}+$ tidal flats \\
\hline $22 / 09 / 11$ & $+\mathrm{BM}$ & Terraço & Cúspides/Mini rips & Ausentes & Ausente & $\mathrm{B}+$ tidal flats \\
\hline
\end{tabular}

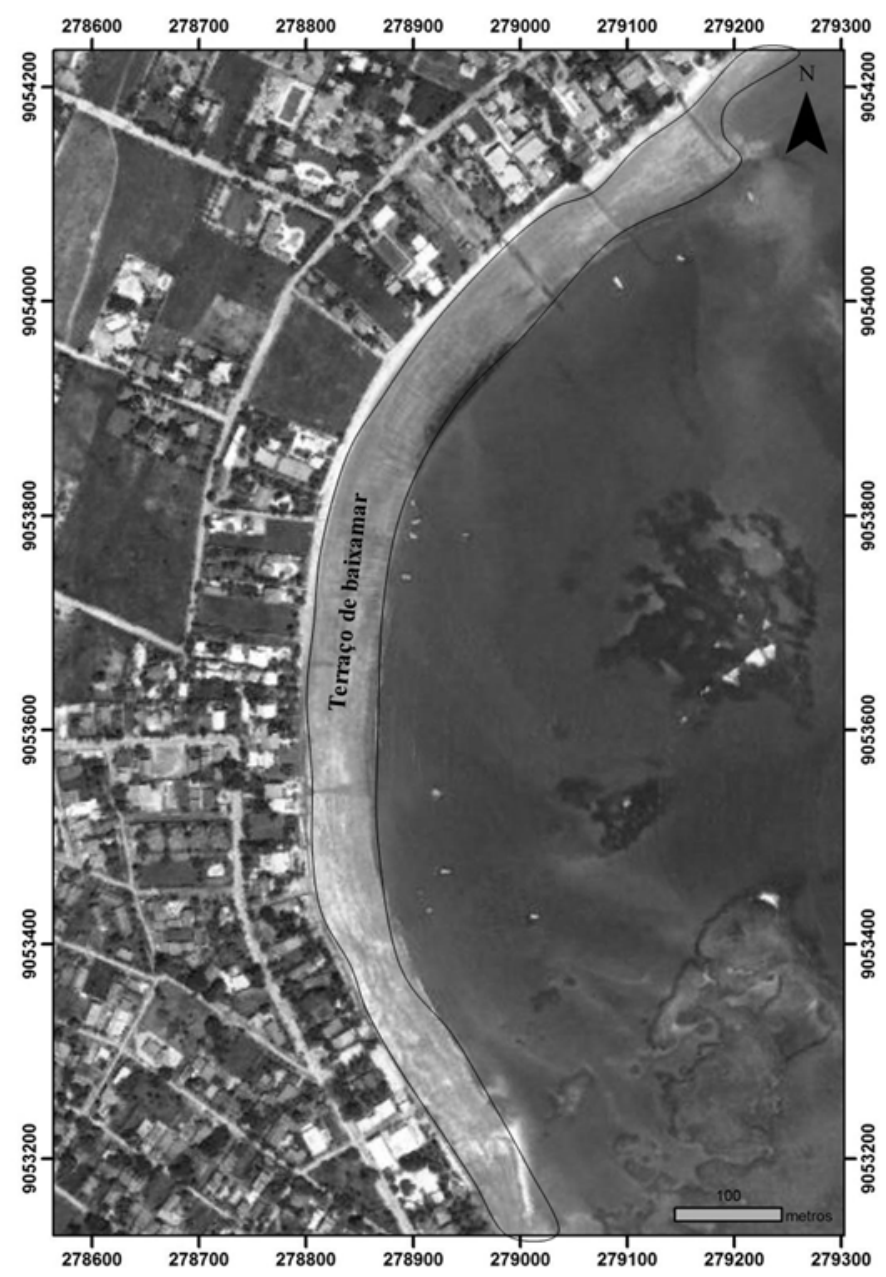

Figura 10. Praia de Maracaípe, apresentando características de terraço de baixamar (25/08/2006). Fuso de referência: 25S. Fonte: Google Earth.

\subsection{Serrambi}

A Praia de Serrambi $(\sim 1,8 \mathrm{~km})$ se apresenta levemente côncava, com sedimentos grossos e pendente íngreme $\left(>5^{\circ}\right)$. No local não há recifes próximos à costa, porém, devido à orientação do arco praial o mesmo é parcialmente protegido da incidência direta de ondas. A tipologia se enquadra naquela descrita para praias modificadas pela maré, sendo que o estágio predominante é o refletivo com terraço de baixamar $(\mathrm{R}+\mathrm{LTT})$ (Tab. 6).

Na imagem de 19/06/2006, a zona de surfe está estreita (entre 5 e $40 \mathrm{~m}$ ) e as ondas arrebentam junto à face praial (Fig. 11A). Não são visíveis bancos, tampouco correntes transversais. Cúspides são observadas na praia e o estado morfodinâmico se assemelha ao refletivo. Em 25/08/2006 a praia apresenta gradação de sudoeste para nordeste. No extremo nordeste do arco praial as características tendem para um terraço de baixamar ao passo que a sudoeste, a praia se torna refletiva, com arrebentação concentrada numa estreita faixa $(<10 \mathrm{~m})$ junto à face praial e presença de cúspides (Fig. 11B, em detalhe). As mesmas observações valem para as demais imagens tomadas na baixamar, sendo que em 14/10/2009, cúspides não estão presentes. Serrambi apresenta características predominantes 
de praia refletiva com terraço de baixamar (R+LTT), além de uma zonação longitudinal do ponto de vista morfodinâmico, na qual é possível distinguir uma região com características de terraço de baixamar (LTT) e outra com características refletivas. Estágios de maior dinâmica, associados a praias dominadas por ondas não foram identificados, o que pode estar relacionado à orientação da praia. Não foram verificadas correntes de retorno e cúspides foram visíveis na maior parte das imagens analisadas (67\%), tomadas na sua maioria durante a baixamar.

Tabela 6. Resumo das características observadas para a Praia de Serrambi.

\begin{tabular}{ccllllc}
\hline Data & $\begin{array}{c}\text { Estágio } \\
\text { maré }\end{array}$ & \multicolumn{1}{c}{ Bancos/Terraço } & Feições na praia & Correntes de Retorno & $\begin{array}{c}\text { Gradação } \\
\text { Classificação } \\
\text { (NE-SO) }\end{array}$ \\
\hline $19 / 06 / 06$ & + PM & Ausente & Cúspides & Ausentes & Ausente & R+LTT \\
$25 / 08 / 06$ & $+B M$ & Presentes & Cúspides & Ausentes & Presente & R+LTT \\
$31 / 08 / 09$ & $+B M$ & Terraço & Cúspides & Ausentes & Presente & R+LTT \\
$14 / 10 / 09$ & $+B M$ & Terraço & Ausentes & Ausentes & Presente & R+LTT \\
$11 / 03 / 10$ & + BM & Terraço & Cúspides & Ausentes & Ausente & R+LTT \\
$20 / 02 / 10$ & $+B M$ & Terraço & Ausentes & Ausentes & Presente & R+LTT \\
$13 / 04 / 10$ & + BM & Presentes & Cúspides & Ausentes & Presente & R+LTT \\
$22 / 09 / 11$ & $+B M$ & Terraço & Cúspides & Ausentes & Presente & R+LTT \\
\hline
\end{tabular}
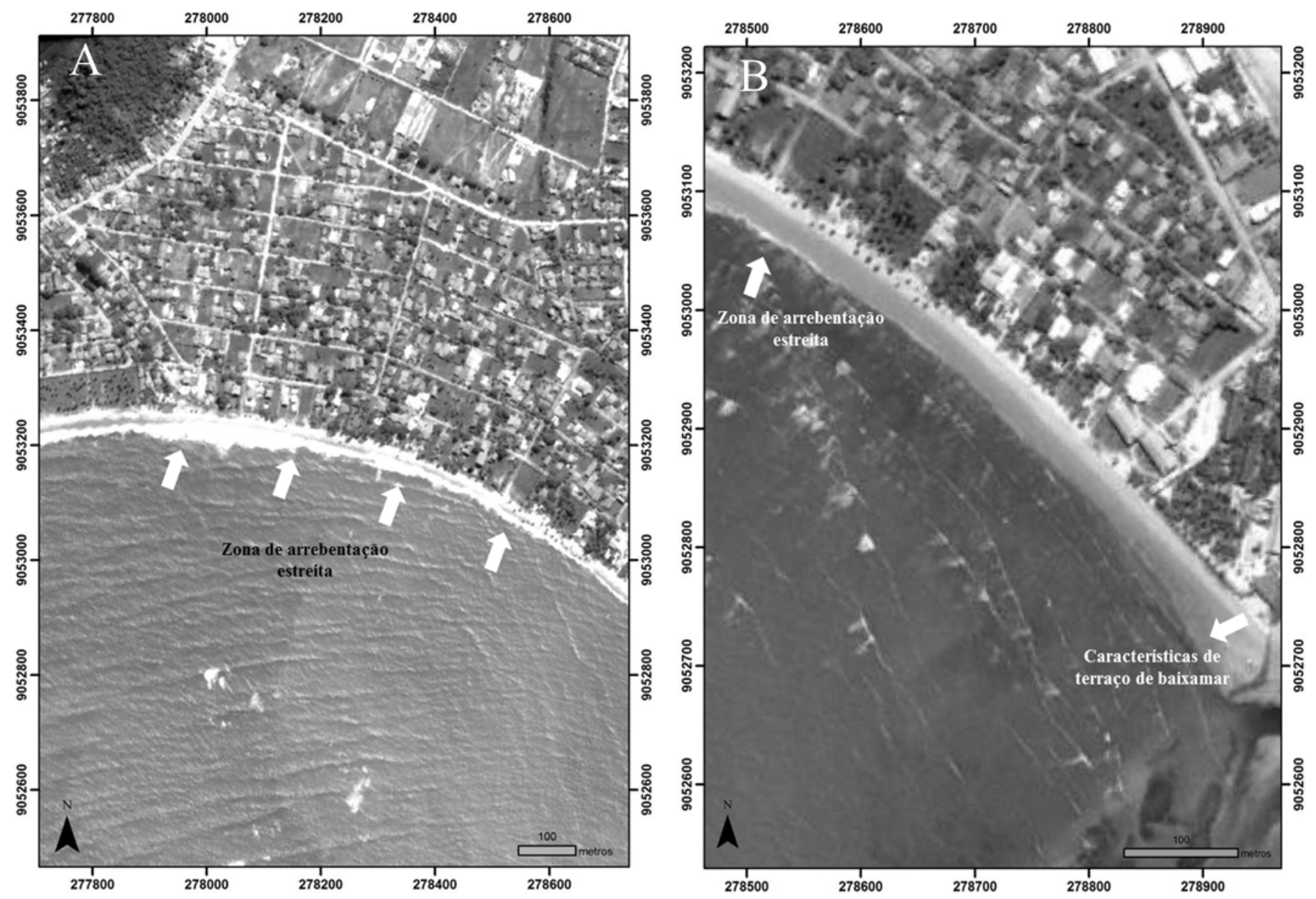

Figura 11. Praia de Serrambi, onde se destacam: A) zona de surfe estreita durante a preamar e ondas arrebentando com turbulência junto à face praial (indicado pelas setas), caracterizando o estágio refletivo (19/06/2006); B) praia apresentando gradação de sudoeste para nordeste, com características de terraço de baixamar e praia refletiva, respectivamente, conforme indicam as setas (25/08/2006). Fuso de referência: 25S. Fonte: Google Earth.

\subsection{Cacimba}

A Praia da Cacimba tem aproximadamente $1,4 \mathrm{~km}$, sendo protegida das ondas por um recife arenítico soldado à costa, o qual dissipa parte da energia de ondas que ali incide. Durante a baixamar, esta estrutura reflete as ondas (Fig. 12) e durante a preamar, a energia é apenas atenuada, o que é possível constatar pela presença de feições cuspatadas junto à praia.

Nesta praia o controle geomorfológico domina os processos morfodinâmicos, o que permite que a mesma seja classificada como associada a recifes em franja (B+ coral reef). Ocorrem, inclusive, as marcas de ondulações já mencionadas para áreas abrigadas por recifes 
junto à Praia de Muro Alto. Observa-se ainda que em virtude da circulação local na zona abrigada, as feições tendem a ser oblíquas e não transversais, como é mais comum em terraços de baixamar. A única ressalva no que se refere à semelhança entre as duas praias é que na Cacimba há evidências de que as ondas atingem a costa durante a preamar, embora não ocorra dissipação junto à face praial.

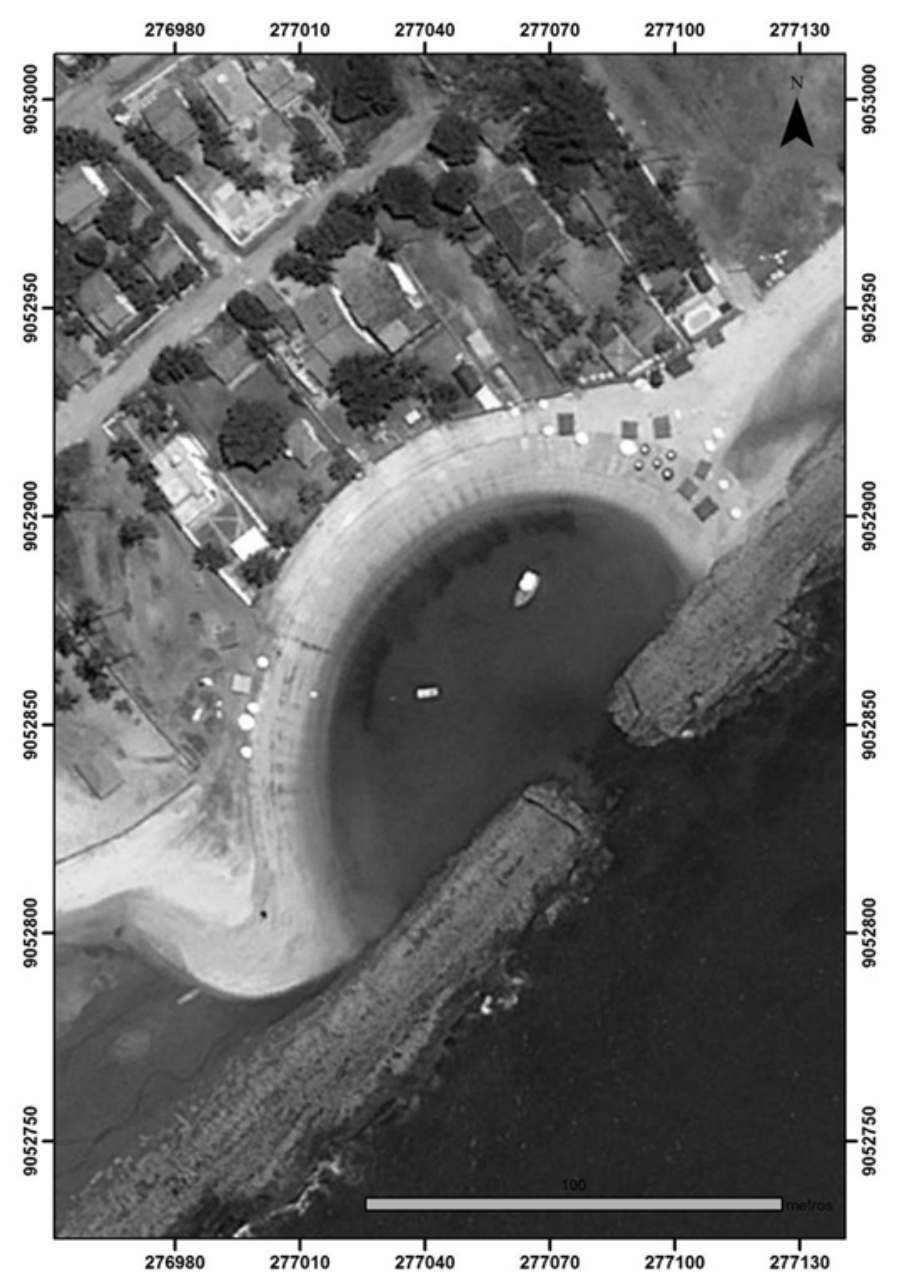

Figura 12. Praia das Cacimbas durante a baixamar, ocasião na qual a praia se encontra protegida da incidência direta das ondas pela presença dos recifes (11/03/2010). Fuso de referência: 25S. Fonte: Google Earth.

\subsection{Toquinho}

Toquinho possui $4,6 \mathrm{~km}$ de litoral protegido por duas linhas contínuas de recifes paralelos à costa, as quais dissipam a energia de onda e abrigam parcialmente a praia. A presença destas estruturas confere uma morfologia sinuosa à linha de costa. A linha de recife externa filtra a energia de ondas que incidem sobre a costa, conforme evidenciam as cúspides. Este segmento parece ter características de praia modificada pela maré, na qual o estágio predominante é aquele descrito como refletivo com terraço de baixamar (R+LTT). Não são observadas feições junto à zona de surfe. Durante a preamar predominam características refletivas (Fig. 13A) e, na baixamar, um terraço permanece exposto (Fig. 13B), apresentando pequenas correntes de retorno.

\section{Discussão}

Após classificação individual, as dez praias foram enquadradas nas quatro tipologias - dominadas por ondas, modificadas pela maré, dominadas pela maré e determinadas pela geomorfologia (Fig. 14).

Apesar da pequena extensão $(<30 \mathrm{~km})$, o litoral de Ipojuca apresenta grande diversidade de ambientes praiais, o que reflete na ocorrência de distintos estágios morfodinâmicos e na dominância das várias forçantes como agentes modeladores. É interessante observar como, sob um mesmo regime de maré e ondas, o litoral de Ipojuca apresenta diferenças na importância relativa de cada agente, o que se dá especialmente em função da orientação da costa e da presença de feições fixas na antepraia (recifes). Estudos semelhantes realizados na Austrália (Short, 2006), em São Paulo e Santa Catarina (Silveira et al., 2011), mostraram, respectivamente, as diversas tipologias praiais localizadas em setores geograficamente afastados ou uma única tipologia. Tal 

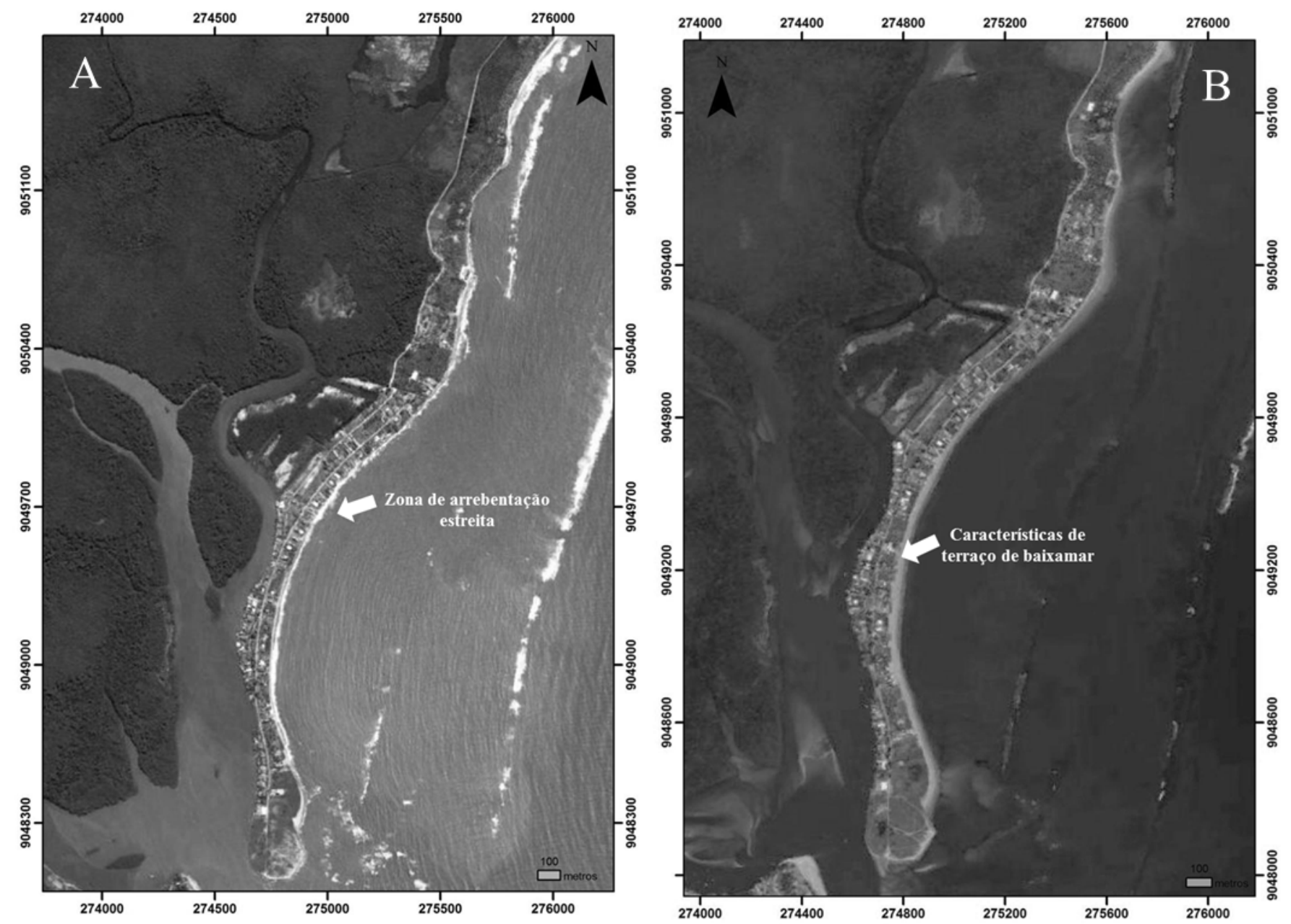

Figura 13. Praia de Toquinho durante os estágios de maré: A) preamar, com características refletivas, como arrebentação estreita e concentrada junto à praia, como mostra a seta; B) baixamar, expondo um terraço (indicado pela seta). Fuso de referência: 25S. Fonte: Google Earth.

constatação confirma a diversidade morfológica/morfodinâmica encontrada nas praias contempladas pelo estudo, conforme discutido a seguir.

\subsection{Praias dominadas por ondas}

Resultados obtidos apontam para a ocorrência, nas praias classificadas nesta tipologia, de estágios morfodinâmicos predominantemente intermediários, com gradações ao longo das praias. De acordo com Short (1999), tais variações são dirigidas por mudanças longitudinais nas características das ondas e pelos processos relacionados, podendo ocorrer nas zonas de empolamento, surfe ou espraiamento. A refração e a difração constituem as principais causas das variações na altura e direção de ondas, de forma que estágios mais energéticos (dissipativo) ocorrem nas porções do arco praial onde as ondas incidem mais diretamente e menos energéticos (refletivo) naquelas mais abrigadas. Nas porções centrais é esperada a ocorrência de estágios intermediários.

Entre as praias nas quais o domínio das ondas como agente modelador da costa é mais nítido figuram Coco Louco, Cupe e Maracaípe. Na primeira, são comuns feições tridimensionais e correntes de retorno, sendo que, de acordo com as imagens analisadas, pode ocorrer transição entre estágios distintos.

No Cupe, a característica morfodinâmica mais frequente é a ocorrência de estágios intermediários. A presença de correntes de retorno é comum, ocorrendo em $100 \%$ das imagens analisadas, assim como a presença de cúspides e megacúspides, o que aponta para o comportamento tridimensional desta praia. Os estágios mais frequentes são banco e praia rítmicos (RBB) e banco transversal e corrente de retorno (TBR) e uma gradação é visível. A influência da maré é nítida, não apenas produzindo distintos estágios, como também estágios transicionais ou com características não tão marcantes quanto aquelas propostas por Wright \& Short (1984). Apesar da influência da maré, é possível afirmar que o segmento responde bem ao modelo proposto para praias dominadas por ondas.

Já em Maracaípe, a observação mais evidente ao longo da série de imagens é a gradação marcada de norte a sul do arco praial. 0 mesmo é previsto pelos modelos de classificação morfodinâmica sem, no entanto, se adequar àquele proposto por Short (1999), tendo em vista o enquadramento dos setores da praia em distintas tipologias de praia (dominado por ondas na porção central, pela maré a norte e modificado pela maré a sul). 


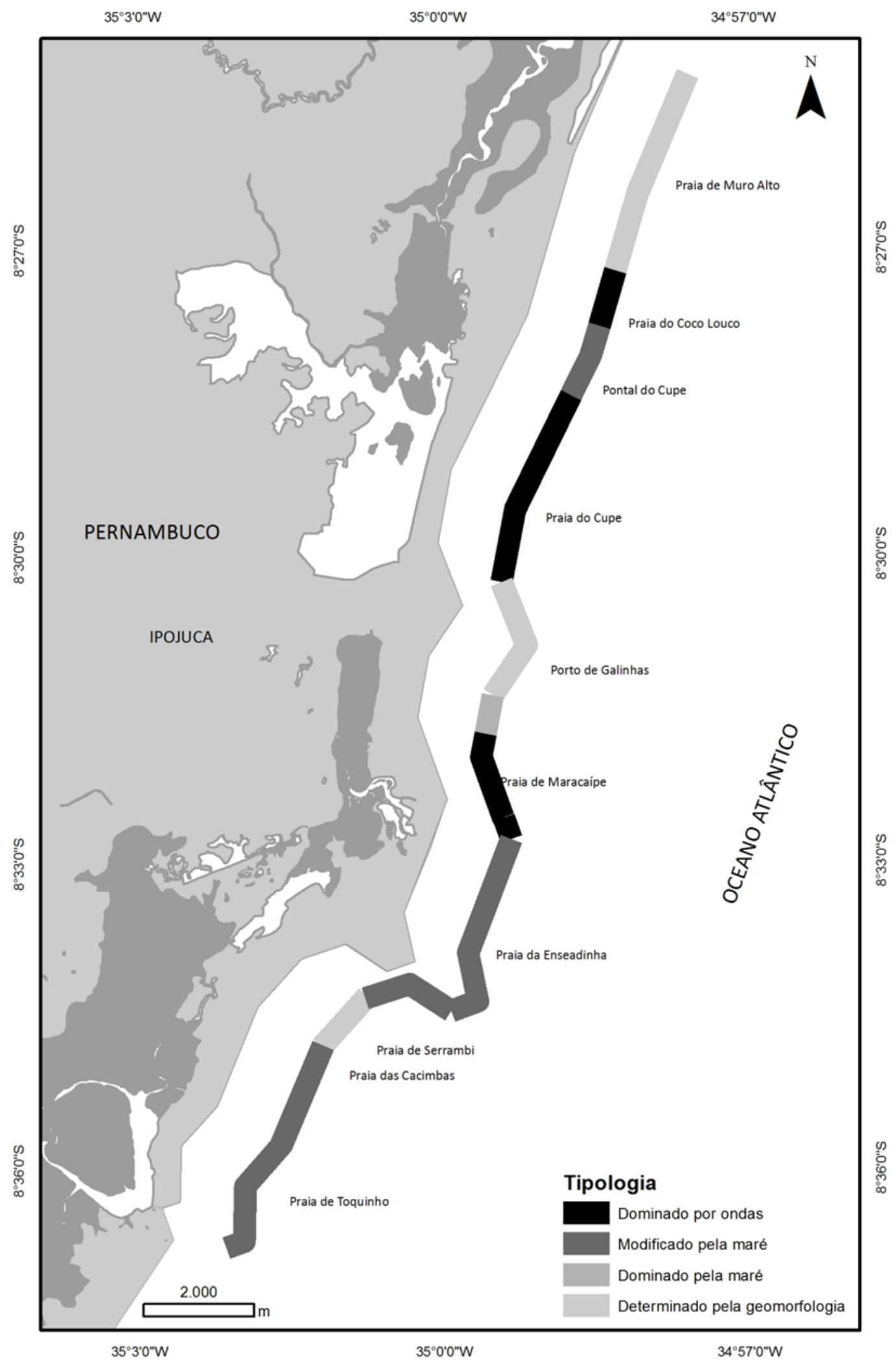

Figura 14. Classificação das praias analisadas quanto à sua tipologia.

Na porção central do arco predomina a ocorrência de um estágio intermediário (RBB ou TBR). A gradação teria ligação direta com os processos de refração/difração sofridos pelas ondas em praias de enseada, ou mesmo em praias bordejadas por promontórios rochosos (no caso, recifes na antepraia). Trabalho anterior realizado em campo por Macedo (2010) corrobora a classificação da porção central do arco como intermediária. 0 autor conclui que o extremo sul possui características dissipativas, com base nas características de declividade e granulometria, e que o extremo norte apresenta características dos estados terraço de baixamar (LTT) e dissipativo. A presença do terraço, de largura média de $\sim 30 \mathrm{~m}$, corrobora a afirmativa de Calliari et al. (2003), de que tal estágio se desenvolve somente em condições ideais, que incluem: partes extremas mais protegidas de longas praias; baías moderadamente abrigadas; ou regiões expostas com areia fina. No entanto, tal classifi- 
cação não considera o efeito da maré, motivo pelo qual não está de acordo com os achados deste estudo, cuja abordagem metodológica considerou a forçante dominante para só então classificar as praias segundo estágios morfodinâmicos.

\subsection{Praias modificadas ou dominadas pela maré}

Masselink (1993) mostra que conforme a variação da maré aumenta, as praias se tornam mais largas, com menor gradiente de declividade e menos feições morfológicas. Esta forçante também contribui com energia através de correntes de maré que podem transportar sedimentos local e regionalmente e influenciar na morfologia da praia e da barreira (Davis \& Hayes, 1984). De acordo com Masselink \& Short (1993), a principal influência da maré sobre a praia consiste na alteração da posição do varrido (swash), do ponto de quebra e da profundidade da antepraia que afetará a altura das ondas. Assim, as marés representam um nível adicional de complexidade à morfodinâmica de praias, por meio da introdução de componentes temporal (ao longo do ciclo) e espacial (perpendicular à costa) às variações morfodinâmicas (Masselink \& Turner, 1999). Tal complexidade fica evidente nas praias de Ipojuca, onde boa parte da extensão estudada apresenta características de praias modificadas (41\%) ou dominadas por esta forçante. Por este motivo, foi considerado o estágio aproximado da maré durante a tomada de cada imagem, o que foi feito com base na observação do grau de exposição da praia e da pós-praia.

Quanto à influência das marés sobre os processos praiais, inúmeros autores já se dedicaram à questão (Short, 1991; Masselink, 1993; Masselink \& Short, 1993; Short, 2006). Estes últimos propuseram um parâmetro adicional para o estudo de ambientes com amplitude de maré moderada a grande, o parâmetro de variação relativa da maré (RTR). Tal parâmetro poderia ser utilizado juntamente com o parâmetro adimensional ômega, proposto anteriormente por Wright \& Short (1984) para a classificação morfodinâmica de praias, considerando o processo dominante em cada litoral se as ondas ou a maré. 0 presente estudo não contemplou o cálculo dos parâmetros supracitados, limitando-se à análise semântica das imagens. Porém, pode-se afirmar que as praias analisadas seguiram o proposto por Short (1991), o qual agrupou as praias de meso e macromaré em três tipos característicos - (i) com alta energia de ondas, plana e de declive uniforme; (ii) com moderada energia de ondas e múltiplos bancos e (iii) com baixa energia de ondas e planícies de maré - sugerindo que um traço comum aos três grupos seria a ocorrência de um padrão mais refletivo por ocasião da preamar e outro mais dissipativo na baixamar.

Praias modificadas ou dominadas pela maré tendem a ocorrer nas porções abrigadas da incidência direta das ondas (Short 2006), o que se enquadra nos achados aqui apresentados. Características comuns incluem uma praia estreita e normalmente íngreme e um terraço intermaré amplo e de baixo gradiente. As praias de Ipojuca classificadas nesta tipologia em função das feições ali presentes encontram-se sob influência de recifes na antepraia ou em segmentos cuja orientação propicia a atenuação da energia das ondas. Como pontos comuns entre elas, figuram a ausência de feições morfológicas na zona de surfe, tais como bancos e correntes de retorno e a ausência de cúspides junto à praia.

\subsection{Praias determinadas pela geomorfologia ou associa- das a recifes}

Outro fator que introduz complexidade às praias contempladas pelo estudo é a ocorrência de recifes. Tais estruturas criam ambientes abrigados, nos quais não é possível aplicar o modelo descrito por Wright \& Short (1984) devido à ausência de feições morfológicas comuns em locais com zona de surfe ativa. Por este motivo, embora não apresentem recifes em franja propriamente, foi utilizada a classificação proposta por Short (2006) para praias associadas a recifes em franja. Cabe aqui observar que o que ocorre neste trecho do litoral, como é típico do nordeste do Brasil, é a presença de recifes de arenito localizados na antepraia e utilizados como substratos para a colonização por corais e algas coralíneas (Dominguez et al., 1990).

O litoral de Pernambuco tem como característica mais conspícua a presença de recifes areníticos, estruturas fixas situadas paralelamente à linha de costa e que podem ou não apresentar descontinuidades, bem como colonização biogênica. Neste último caso, os mesmos desenvolvem morfologia mais complexa, como manchas, estando associadas às saliências na costa, tal como observado em Porto de Galinhas. Os recifes têm o potencial de alterar a hidrodinâmica local e dissipar energia de onda, desempenhando assim, um importante papel na morfologia recente da costa (Ramanujam \& Sudarsan, 2003). 0 nível de atenuação da energia de ondas, por sua vez, está relacionado à geometria e ao grau de submersão do corpo recifal (Shirlal \& Manu, 2007; Borba, 2011). Após a passagem pelo recife, ocorre uma área de baixa hidrodinâmica, na qual é possível se observar formas de fundo transversais à costa. Tais feições se verificam em dois segmentos classificados nesta tipologia, Muro Alto e Cacimbas. Araújo et al. (2008), estudando formas de fundo em área protegida por recifes, em Tamandaré (PE), concluíram que tais formas seriam determinadas preponderantemente pela atuação de ondas e correntes, com pouca ou nenhuma influência fluvial ou da maré, o que reforça a combinação entre estas forçantes como determinante da posição e forma das marcas de ondulação observadas.

\section{Conclusões}

A análise das praias do município de Ipojuca permitiu observar que, na área, a tipologia praial está inti- 
mamente relacionada à presença de recifes e à orientação da linha de costa. Tais fatores também mostraram considerável influência sobre a gradação longitudinal de algumas praias, em especial àquelas em forma de arco.

A interpretação de imagens mostrou-se uma forma de baixo custo e de fácil execução para classificar praias segundo estados morfodinâmicos. No entanto, tal como mencionado por Silveira et al. (2011), é necessário que se tenha acesso a boas imagens e que os intérpretes sejam treinados e experientes. É interessante ainda que as imagens sejam analisadas por mais de um intérprete. Ademais, é preciso considerar que as imagens representam um instantâneo, o momento de captura da imagem e que a praia está sujeita a variações em função do estado de mar, das condições meteorológicas e do estágio da maré.

O modelo de Wright \& Short (1984), amplamente utilizado em estudos de praias arenosas, não é suficiente para a classificação morfodinâmica de litorais tão diversos quanto o aqui estudado, podendo incorrer em erros. Neste sentido, destaca-se que durante estágios de preamar, as estruturas recifais podem produzir morfologias na zona de surfe semelhantes àquelas observadas em praias arenosas com bancos, o que aumenta a necessidade de se conhecer a morfologia da antepraia previamente ao uso de tais modelos, bem como de se verificar a aplicabilidade dos modelos às áreas de estudo.

Embora o modelo supracitado seja aplicável às porções do litoral expostas à ação das ondas, em regiões nas quais a importância relativa da maré aumenta e/ou naquelas associadas a recifes, é necessário que se tenha um maior critério ao enquadrar praias em classificações morfodinâmicas. Neste aspecto, os modelos sugeridos por Masselink \& Short (1993) e Short (2006) vieram a complementar a abordagem metodológica adotada e permitir que todas as praias com suas particularidades fossem classificadas.

Por fim, ressalta-se a importância de se estudar a zona de surfe e a vocação da análise semântica de imagens para tanto. Boa parte dos processos que controlam a morfologia e a hidrodinâmica da praia estão associados à dissipação de energia nesta região. No litoral pernambucano, embora inúmeros estudos se dediquem às variações morfológicas das praias poucos são os que contemplam o estudo da antepraia. A metodologia aqui aplicada e outras semelhantes são de grande utilidade e eficiência na abordagem de problemas costeiros, tendo em vista seu baixo custo e rápida obtenção de resultados, particularmente no litoral de Pernambuco, onde problemas como acidentes envolvendo banhistas e erosão costeira são frequentes.

\section{Referências}

Araújo, A.M., Costa, M.B.S.F., Macedo, E.C. \& Cantalice, J.R.B. 2008. Formas de fundo em águas costeiras e estudos de ondas e correntes locais. In: ENCONTRO NACIONAL DE
ENGENHARIA DE SEDIMENTOS, 8, Anais..., Campo Grande, v. 1, p. 1-13.

Borba, M. 2011. Influência da estrutura recifal na transformação das ondas do litoral de Recife e Jaboatão dos Guararapes/PE - Brasil. 130p. Dissertação de Mestrado, Programa de Pós-graduação em Oceanografia, Departamento de Oceanografia, Universidade Federal de Pernambuco.

Calliari, L.J. \& Klein, A.H.F. 1993. Variabilidade das praias oceânicas entre Cassino e Chui, RS. Pesquisas, 20 (1):48-53.

Calliari, L.J., Muehe, D., Hoefel, F.G. \& Toldo Jr., E. 2003. Morfodinâmica praial: uma breve revisão. Revista Brasileira de Oceanografia, 51:63-78.

Davis, R.A. \& Hayes, M.O. 1984. What is a wave dominated coast? Marine Geology, 60:313-329.

Dominguez, J.M.L., Bittencourt, A.C.S.P., Leão, Z.M.S.N. \& Azevedo, A.E.G. 1990. Geologia do Quaternário costeiro do estado de Pernambuco. Revista Brasileira de Geociências, 20: 208-215.

ESRI. Environmental Systems Research Institute, Inc. 2009. ArcGIS. Professional GIS for desktop, versão 9.2, Redlands, ESRI. 1 CD-ROM.

Google Earth vs. 7.1.1.1888 for Windows. 2012. Google Inc. Disponível em: <http://www.google.com.br/intl/pt-BR/ earth>. Acessado em: 18 mai. 2012.

Macedo, R.J.A. 2010. Caracterização morfodinâmica e geoambiental da praia de Maracaípe, Ipojuca, PE. Recife, 143p. Dissertação de Mestrado, Programa de Pós-graduação em Geociências, Departamento de Geociências, Universidade Federal de Pernambuco.

Mallmann, D.L.B., Nunes, K.C., Sa, L.A. \& Araujo, T.C.M. 2011. Atlas de sensibilidade ambiental ao óleo do litoral de Pernambuco. Recife, Liceu, 208p.

Manso,V.A.V. 2003. Definição dos pontos de contorno da linha de preamar máxima atual do município de Ipojuca - PE. Recife, UFPE, 36p. (Relatório técnico).

Masselink, G. 1993. Simulating the effects of tides on beach morphodynamics. Journal of Coastal Research, SI 15:180197.

Masselink, G. \& Short, A.D. 1993. The effect of tide range on beach morphodynamics and morphology: a conceptual beach model. Journal of Coastal Research, 9(3):785-800.

Masselink, G. \& Turner, I. 1999. The effect of tides on beach morphodynamics. In: Short, A.D. (Ed.) Handbook of beach and shoreface morphodynamics. Chichester, Wiley, $379 \mathrm{p}$.

Ramanujam, N. \& Sudarsan, A.R. 2003. A study of coastal transformation at Tuticorin as a result of emerged and submerged natural breakwaters of Van Island, Gulf of Mannar. Environmental Geology, 43:521-525.

Shirlal, K.G. \& Manu, S.R. 2007. Ocean wave transmission by submerged reef - a physical model study. Ocean Engineering, 34: 2093-2099.

Short, A.D. 1991. Macro-meso tidal beach morphodynamics - an overview. Journal of Coastal Research, 7(2):417-436.

Short, A. D. 1999. Handbook of Beach and Shoreface Morphodynamics. Chichester, Wiley, $379 \mathrm{p}$.

Short, A.D. 2006. Australian beach systems - nature and distribution. Journal of Coastal Research, SI 22:11-27.

Short, A.D. \& Hogan, C.L. 1994. Rip currents and beach hazards: their impact on public safety and implications for coastal management. Journal of Coastal Research, SI 12:197-209.

Silveira, L F., Klein, A.H.F. \& Tessler, M.G. 2011. Classificação morfodinâmica das praias do estado de Santa Catarina e do litoral norte do estado de São Paulo utilizando senso- 
riamento remoto. Brazilian Journal of Aquatic Science and Technology, 15(2):13-28.

SLSA (OzCoasts). 2009. Australian Beach Safety and Management Program database. Disponível em: <http://www. ozcoasts.gov.au/coastal/beach_intro.jsp> Acessado em:

Manuscrito 534.

Editores: Iran C. S. Corrêa \& Paulo A. Souza.
20 ago. 2013.

Wright, L.D. \& Short, A.D. 1984. Morphodynamic variability of surf zones and beaches: a synthesis. Marine Geology, 56:93-118. 
